$\mathcal{S}_{\text {doi: 10.3765/sp.3.1 }}^{\text {Semantics \& Pragmatics Volume 3, Article 1: 1-72, } 2010}$

\title{
Quantifiers in than-clauses*
}

\author{
Sigrid Beck \\ University of Tübingen
}

Received 2009-01-13 / First Decision 2009-03-17 / Revised 2009-06-17 / Second Decision 2009-07-06 / Revised 2009-07-27 / Accepted 2009-07-27 / Published 201001-25

\begin{abstract}
The paper reexamines the interpretations that quantifiers in than-clauses give rise to. It develops an analysis that combines an interval semantics for the than-clause with a standard semantics for the comparative operator. In order to mediate between the two, interpretive mechanisms like maximality and maximal informativity determine selection of a point from an interval. The interval semantics allows local interpretation of the quantifier. Selection predicts which interpretation this leads to. Cases in which the prediction appears not to be met are explained via recourse to independently attested external factors (e.g. the interpretive possibilities of indefinites). The goal of the paper is to achieve coverage of the relevant data while maintaining a simple semantics for the comparative. A secondary objective is to reexamine, restructure and extend the set of data considered in connection with the problem of quantifiers in than-clauses.
\end{abstract}

Keywords: comparatives, degrees, intervals, quantifiers, indefinites, plurals, scope

* Versions of this paper were presented at the workshop on covert variables in Tübingen 2006, at two Semantic Network meetings (in Barcelona 2006 and Oslo 2007), at the 2009 Topics in Semantics seminar at MIT, and at the Universität Frankfurt 2009. I would like to thank the organizers Frank Richter and Uli Sauerland and the audiences at these presentations for important feedback. Robert van Rooij and Jon Gajewski have exchanged ideas with me. The B17 project of the SFB 441 has accompanied the work presented here-Remus Gergel, Stefan Hofstetter, Sveta Krasikova, John Vanderelst - as have Arnim von Stechow and Irene Heim. Several anonymous reviewers and Danny Fox have given feedback on earlier versions, and David Beaver and Kai von Fintel have commented on the prefinal version. I am very grateful to them all.

(C)2010 Sigrid Beck

This is an open-access article distributed under the terms of a Creative Commons NonCommercial License (creativecommons.org/licenses/by-nc/3.o). 
Sigrid Beck

\section{Introduction}

The problem of quantifiers in than-clauses has been puzzling linguists for a long time, beginning with von Stechow 1984, via Schwarzschild \& Wilkinson 2002, Schwarzschild 2004, and Heim 2006b, to very recent approaches in Gajewski 2008, van Rooij 2008 and Schwarzschild 2008. It can be illustrated with the examples below.

(1) John ran faster than every girl did.

$\left(1^{\prime}\right) \quad$ a. For all $x, x$ is a girl: John ran faster than $x$.

b. \#The degree of speed that John reached exceeds the degree of speed that every girl reached.

i.e. "John's speed exceeds the speed of the slowest girl."

(2) John ran faster than he had to.

$\left(2^{\prime}\right) \quad$ a. \#For all $w, w$ is a permissible world: John ran faster in @ than he ran in $w$.

b. The degree of speed that John reached in @ exceeds the degree of speed that he has in every permissible world $w$.

i.e. "John's actual speed exceeds the slowest permissible speed."

(@ stands for the real world)

Example (1) intuitively only has a reading that appears to give the universal NP scope over the comparison, namely ( $\left.1^{\prime} \mathrm{a}\right)$ : all the girls were slower than John. The reading in which the universal NP takes narrow scope relative to the comparison is paraphrased in $\left(1^{\prime} b\right)$. Here we must look at degrees of speed reached by all girls; depending on the precise semantics of the thanclause (see below), this could mean the maximal speed that they all reached, i.e. the speed of the slowest girl. Example (1) has no reading that compares John's speed to the speed of the slowest girl. Sentence (2), on the other hand, only has a reading that gives the modal universal quantifier narrow scope relative to the comparison, $\left(2^{\prime} \mathrm{b}\right)$. That is, we consider the degrees of speed that John reaches in all worlds compatible with the rules imposed by the modal base of have to. This will yield the slowest permissible speed, and (2) intuitively says that John's actual speed exceeded this minimum requirement. The sentence is not ${ }^{1}$ understood to mean that John did something that was

1 Heim (2006b) and Krasikova (2008) include a discussion of when readings like (2'a) are available. The reading can be made more plausible with a suitable context, depending on the modal chosen. For the moment I will stick to the simpler picture presented in the text. See 
Quantifiers in than-clauses

against the rules - that is, reading ( $\left.2^{\prime} \mathrm{a}\right)$, in which the modal takes scope over the comparison, is not available.

We must ask ourselves how a quantifier contained in the than-clause can have wide scope at all, why it cannot get narrow scope in (1), and why (2) is the opposite. Since - as we will see in more detail below - these questions look unanswerable under the standard analysis of comparatives, the researchers cited above have been led to a revision of the semantic analysis of comparison. Schwarzschild \& Wilkinson (2002) employ an interval semantics for the thanclause and give the comparative itself an interval semantics. Heim (2006b) adopts intervals, but ultimately reduces the semantics of the comparison back to a degree semantics through semantic reconstruction. This allows her to retain a simple meaning of the comparative operator. A than-clause internal operator derives the different readings that quantifiers in thanclauses give rise to. The line of research in Gajewski 2008, van Rooij 2008 and Schwarzschild 2008 in turn adopts the idea of a than-clause internal operator but not the intervals.

In this paper, I pursue a strategy that can be seen as an attempt to simplify Schwarzschild \& Wilkinson's proposal. Like them, I derive a meaning for the than-clause without a than-clause internal operator, and that meaning is based on an interval semantics. But I combine this with a standard semantics of the comparative in the spirit of von Stechow 1984. This means that the end result of interpreting the than-clause must be a degree. Everything will hinge on selecting the right degree, so that each of the relevant examples receives the right interpretation.

In Section 2, I present the current state of our knowledge in this domain. The analysis of than-clauses is presented in Section 3. Section 4 ends the paper with a summary and some discussion of consequences of the proposed analysis.

\section{State of affairs}

I first present a sample of data that I take to be representative of the interpretational possibilities that arise with quantifiers in than-clauses. Then I sketch Schwarzschild \& Wilkinson's (2002) and Heim's (2006b) analyses in Section 2.2, and in Section 2.3 a summary of the proposals in Gajewski 2008, van Rooij 2008 and Schwarzschild 2008.

Section 3 for more discussion. 
Sigrid Beck

\subsection{The empirical picture}

\subsubsection{A classical analysis of the comparative}

The basis of our present perception of the problem presented by (1) and (2) is the analysis of the comparative construction, because the data are understood in terms of whether the quantfier appears to take wide scope over the comparison according to a classical analysis of the comparative, or whether it would have to be seen as taking narrow scope relative to the comparison. My presentation assumes a general theoretical framework like Heim \& Kratzer 1998 and begins with specifically Heim's (2001) version of the theory of comparison promoted in von Stechow 1984 (see also Klein 1991 and Beck 2009 for an exposition and Cresswell 1977; Hellan 1981; Hoeksema 1983; Seuren 1978 for theoretical predecessors). This theory is what I will refer to as a classical analysis of the comparative. For illustration, I discuss the simple example (3a) below. In (3b) I provide the Logical Form and in (3c) the truth conditions derived by compositional interpretation of that Logical Form, plus paraphrase. Interpretation relies on the lexical entries of the comparative morpheme and gradable adjectives as given in (4).

(3) a. Paule is older than Knut is.

$\begin{aligned} \text { b. } \quad[\text {-er } \quad[\langle d, t\rangle & \text { than } & 2 & \left.\left.\text { [Knut is } t_{2} \text { old }\right]\right] \\ & {[\langle d, t\rangle} & 2 & \left.\left.\text { [Paule is } t_{2} \text { old }\right]\right]\end{aligned}$

c. $\max (\lambda d$. Paule is $d$-old $)>\max (\lambda d$. Knut is $d$-old $)=$

$$
\text { Age (Paule) }>\text { Age(Knut) }
$$

"The largest degree of age that Paule reaches exceeds the largest degree of age that Knut reaches."

"Paule’s age exceeds Knut's age."

(4) a. $\llbracket$-er $\rrbracket=\lambda D_{\langle d, t\rangle} \cdot \lambda D_{\langle d, t\rangle}^{\prime} \cdot \max \left(D^{\prime}\right)>\max (D)$

b. $\llbracket$ old $\rrbracket_{\langle d,\langle e, t\rangle\rangle}=[\lambda d \cdot \lambda x \cdot x$ is $d$-old $]$

$=[\lambda d \cdot \lambda x \cdot \operatorname{Age}(x) \geq d]$

c. Let $S$ be a set ordered by $R$.

$$
\text { Then } \max _{R}(S)=\iota s\left[s \in S \& \forall s^{\prime} \in S\left[s R s^{\prime}\right]\right]
$$

Importantly, the role of the comparative operator is ultimately to relate the maximal degree provided by the than-clause to some matrix clause degree. The than-clause provides degrees through abstraction over the degree argument slot of the adjective. Different versions of such a classical analysis are available (for instance von Stechow's (1984) own or Kennedy's 
(1997)), but the problem of quantifiers in than-clauses presents itself in a parallel fashion in all of them.

I will make one small revision to the above version of the classical analysis: I will suppose that what is written into the lexical entry of the comparative morpheme as the maximality operator in (4a) is not actually part of the meaning of the comparative itself. Rather, it is a general mechanism that allows us to go from a description of a set to a particular object, for example also in the case of free relative clauses in (5) (Jacobson 1995); see also Beck 2009. I represent maximality in the Logical Form, as indicated in $\left(4^{\prime} b\right)$. The meaning of the comparative is then simply $\left(4^{\prime} a\right)$, the 'larger than' relation. It is basically this meaning of the comparative that I will try to defend below. The resulting interpretation remains of course the same.

(5) a. We bought [what we liked].

b. $\max (\lambda x$. we liked $x)$

(4') $\quad$ a. $\quad \llbracket-e r \rrbracket=\lambda d_{d} \cdot \lambda d_{d}^{\prime} \cdot d^{\prime}>d$

b. [-er $\left[d\right.$ than $\max 2$ [Knut is $t_{2}$ old] $]$

[d $\quad \max 2$ [Paule is $t_{2}$ old]]]

c. $\max (\lambda d$. Paule is $d$-old $)>\max (\lambda d$. Knut is $d$-old $)$

\subsubsection{Apparent wide scope quantifiers}

Universal NPs are a standard example for an apparent wide scope quantifier (see e.g. Heim 2006b). The sentence in (6) below only permits the reading in $\left(6^{\prime} \mathrm{a}\right)$, not the one in $\left(6^{\prime} \mathrm{b}\right)$. This can be seen from the fact that the sentence would be judged false in the situation depicted below.

(6) John is taller than every girl is.

$\left(6^{\prime}\right) \quad$ a. $\quad \forall x[\operatorname{girl}(x) \rightarrow \max (\lambda d$. John is $d$-tall $)>\max (\lambda d . x$ is $d$-tall $)]$

"For every girl $x$ : John's height exceeds $x$ 's height."

b. $\# \max (\lambda d$. John is $d$-tall $)>\max (\lambda d . \forall x[\operatorname{girl}(x) \rightarrow x$ is $d$-tall $])$

"John's height exceeds the largest degree to which every girl is tall."

"John is taller than the shortest girl."

$$
\text { g1's height J's height } \quad g_{2} \text { 's height } \quad g_{3} \text { 's height }
$$


The classical semantics of comparatives makes this look as if the NP had to take scope over the comparative. The LF given in (6"a) can straightforwardly be interpreted to yield $\left(6^{\prime} a\right)$; analogously for $\left(6^{\prime \prime} b\right)$ and $\left(6^{\prime} b\right)$. Thus, strangely, the sentence appears to permit with (6"a) only an LF which violates constraints on Quantifier Raising (QR): QR is normally confined to a simple finite clause (May 1985 and much subsequent work). The LF in (6"b), which would be unproblematic syntactically, is not possible.

$\left(6^{\prime \prime}\right) \quad$ a. [[every girl] [1 [[-er $\left[{ }_{d}\right.$ than $\max 2\left[t_{1}\right.$ is $t_{2}$ tall] $]$ [d $\quad \max 2$ [John is $t_{2}$ tall]]]]

b. [[-er $\quad\left[d\right.$ than $\max 2$ [every girl] [ $1\left[t_{1}\right.$ is $t_{2}$ tall]]] [d $\quad \max 2$ [John is $t_{2}$ tall]]]

The example with the differential in (7) shows the same behaviour (it uses a version of the comparative that accomodates a difference degree, (7c)).

(7) a. John is $2^{\prime \prime}$ taller than every girl is.

b. $\forall x\left[\operatorname{girl}(x) \rightarrow \max (\lambda d\right.$. John is $d$-tall $) \geq \max (\lambda d$. $x$ is $d$-tall $\left.)+2^{\prime \prime}\right]$ $=$ For every girl $x$ : John's height exceeds $x$ 's height by $2^{\prime \prime}$.

c. $\llbracket-\mathrm{er}_{\mathrm{diff}} \rrbracket=\lambda d \cdot \lambda d^{\prime} \cdot \lambda d^{\prime \prime} . d^{\prime \prime} \geq d+d^{\prime}$

The problem posed by (5) and (7) is exacerbated in (8), as Schwarzschild \& Wilkinson (2002) observe. We have once more a universal quantifier, but this time it is one that is taken to be immobile at LF: the intensional verb predict. Still, the interpretation that is intuitively available looks to be one in which the universal outscopes the comparison, $\left(8^{\prime} a\right)$. The interpretation in which comparison takes scope over predict, $\left(8^{\prime} \mathrm{b}\right)$, is not possible. This is problematic because the LF we would expect (8) to have is (10), and (10) is straightforwardly interpreted to yield $\left(8^{\prime} \mathrm{b}\right)$.

(8) John is taller than I had predicted (that he would be).

(9) My prediction: John will be between $1.70 \mathrm{~m}$ and $1.80 \mathrm{~m}$.

Claim made by (8): John is taller than $1.80 \mathrm{~m}$.

$\left(8^{\prime}\right) \quad$ a. $\quad \forall w[w R @ \rightarrow$

$\max (\lambda d$. John is $d$-tall in @ $)>\max (\lambda d$. John is $d$-tall in $w)]$ "For every world compatible with my predictions: John's actual height exceeds John's height in that world."

b. \# $\max (\lambda d$. John is $d$-tall in @)

$$
>\max (\lambda d . \forall w[w R @ \rightarrow \text { John is } d \text {-tall in } w])
$$


Quantifiers in than-clauses

"John's actual height exceeds the degree of tallness which he has in all worlds compatible with my predictions."

"John's actual height exceeds the shortest prediction, 1.70 m."

(where $R$ is the relevant accessibility relation, compare e.g. Kratzer 1991)

(10) $\quad\left[\left[-e r ~\left[\langle d, t\rangle \quad\right.\right.\right.$ than $\max 2$ [ I had predicted that [ John be $t_{2}$ tall]]]

[ $\langle d, t\rangle \quad \max 2$ [ John is $t_{2}$ tall]]]

This is the interpretive behaviour of many quantified NPs, plural NPs like the girls, quantificational adverbs, verbs of propositional attitude and some modals (e.g. should, ought to, might). See Schwarzschild \& Wilkinson 2002 and Heim 2006b for a more thorough empirical discussion.

\subsubsection{Apparent narrow scope quantifiers}

Not all quantificational elements show this behaviour. A universal quantifier that does not is the modal have to, along with some others (be required, be necessary, need). This is illustrated below.

(11) Mary is taller than she has to be.

(12) Mary wants to play basketball. The school rules require all players to be at least $1.70 \mathrm{~m}$. Claim made by (11): Mary is taller than $1.70 \mathrm{~m}$.

(11') a.?\# $\forall w[w R @ \rightarrow$ $\max (\lambda d$. Mary is $d$-tall in @ $)>\max (\lambda d$. Mary is $d$-tall in $w)]$ $=$ For every world compatible with the school rules:

Mary's actual height exceeds Mary's height in that world; i.e. Mary is too tall.

b. $\max (\lambda d$. Mary is $d$-tall in @ $)$

$$
>\max (\lambda d . \forall w[w R @ \rightarrow \text { Mary is } d \text {-tall in } w])
$$

= Mary's actual height exceeds the degree of tallness which she has in all worlds compatible with the school rules;

i.e. Mary's actual height exceeds the required minimum, $1.70 \mathrm{~m}$.

These modals permit what appears to be a narrow scope interpretation relative to the comparison. Example (11) does not favour an apparent wide scope interpretation. Krasikova (2008) argues though that some examples with have to-type modals may have both readings, depending on context. (13) is one of her examples favouring a reading analogous to (11'a), an apparent 
wide scope reading of have to (see Section 3 for more discussion).

(13) He was coming through later than he had to if he were going to retain the overall lead. (from Google, cited from Krasikova 2008) $=$ He was coming through too late.

Existential modals like be allowed also appear to take narrow scope:

(14) Mary is taller than she is allowed to be.

(15) $\quad$ a. $\# \exists w[w R @ \&$ $\max (\lambda d$. Mary is $d$-tall in @ $)>\max (\lambda d$.Mary is $d$-tall in $w)]$ $=$ It would be allowed for Mary to be shorter than she actually is. b. $\max (\lambda d$. Mary is $d$-tall in @)

$>\max (\lambda d . \exists w[w R @ \&$ Mary is $d$-tall in $w])$ = Mary's actual height exceeds the largest degree of tallness that she reaches in some permissible world; i.e. Mary's actual height exceeds the permitted maximum.

And so do some other existential quantifiers and disjunction:

(16) Mary is taller than anyone else is.

(17) a. \#There is someone that Mary is taller than.

b. Mary's height exceeds the largest degree of tallness reached by one of the others.

(18) Mary is taller than John or Fred are.

(19) a.?\#For either John or Fred: Mary is taller than that person.

b. Mary's height exceeds the maximum height reached by John or Fred.

This is the interpretive behaviour of some modals (e.g. need, have to, be allowed, be required), some indefinites (especially NPIs) and disjunction (compare once more Heim 2006b). It is also the behaviour of negation and negative quantifiers, with the added observation that the apparent narrow scope reading is one which often gives rise to undefinedness, hence unacceptability (von Stechow 1984; Rullmann 1995). (That this is not invariably the case is shown by (22), illustrating that we are concerned with a constraint on meaning rather than form.)

(20) *John is taller than no girl is. 
Quantifiers in than-clauses

(21) a. John's height exceeds the maximum height reached by no girl. The maximum height reached by no girl is undefined, hence: unacceptability of this reading.

b. \#There is no girl who John is taller than.

(22) I haven't been to the hairdresser longer than I haven't been to the dentist.

Here is how the empirical picture presents itself from the point of view of a classical analysis of comparatives. It appears that there are two different scope readings possible for quantifiers embedded inside the than-clause, wide or narrow scope relative to the comparison. But there is usually no ambiguity. Each individual quantifier favours at most one reading (negation frequently permits none). Apparent narrow scope readings are straightforwardly captured by the classical analysis. It is unclear how apparent wide scope readings are to be derived at all. As Schwarzschild \& Wilkinson argue, they are beyond the reach of an LF analysis. It is also unclear what creates the pattern in the readings that we have observed.

Before we examine modern approaches to this problem, a final comment on the data. I have presented them the way they are presented in the literature on the subject, as if they were all impeccable and their interpretations clear. But I would like to use this opportunity to point out that I find some of them fairly difficult and perhaps not even entirely acceptable. This concerns example (6), for which I would much prefer a version with a definite plural (the girls instead of every girl). The NP the girls is, if anything, more problematic under the classical analysis, as Schwarzschild \& Wilkinson (2002) point out (having less of an inclination towards wide scope); but see Section 4 for a comment on how this issue may be relevant for the analysis developed in this paper.

$\left(6^{\prime \prime \prime}\right)$ a. ?John is taller than every girl is.

b. John is taller than the girls are. $\forall x[x \in \llbracket$ the girls $\rrbracket \rightarrow$ John is taller than $x]$

Another instance are examples with intensional verbs like predict or expect; when a genuine range is predicted or expected, intuitions regarding when sentences with differentials like $\left(8^{\prime \prime}\right)$ would be true vs. false are not very firm. This seems to me an area in which a proper empirical study might be helpful. The issue is taken up in Section 3.4. 
$\left(8^{\prime \prime}\right)$ a. John is two inches taller than I had predicted (that he would be).

b. John arrived at most 10 minutes later than I had expected.

\subsection{New analyses I}

Since it is very hard to see how the data can be derived under the classical theory, the two theories summarized below (Schwarzschild \& Wilkinson 2002 and Heim 2006b) both change the semantics of the comparative construction in ways that reanalyse scope. The quantificational element inside the thanclause can take scope there even under the apparent wide scope reading. The two theories differ with respect to the semantics they attribute to the comparison itself. They also differ in their empirical coverage.

\subsubsection{Schwarzschild \& Wilkinson 2002}

Schwarzschild \& Wilkinson (2002) are inspired by the scope puzzle to a complete revision of the semantics of comparison. The feature of the classical analysis that they perceive as the crux of our problem is that the than-clause provides a degree via abstraction over degrees. According to them, the quantifier data show that the than-clause instead must provide us with an interval on the degree scale - in (23) below an interval into which the height of everyone other than Caroline falls.

(23) Caroline is taller than everyone else is.

'Everyone else is shorter than Caroline.'

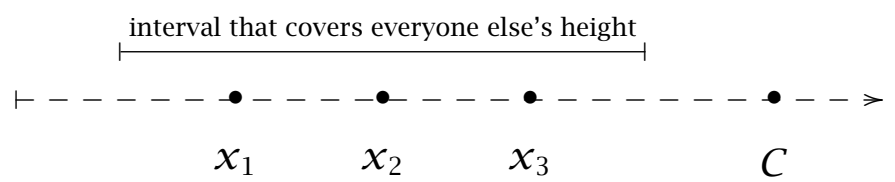

(the interval is related to Caroline's height by the comparative)

(24) 【than everyone else is $\rrbracket=\lambda D$. everyone else's height falls within $D$ (where $D$ is of type $\langle d, t\rangle)^{2}$

To simplify, I will suppose that it is somehow ensured that we pick the right matrix clause interval (Caroline's height in (23), Joe's height in the example

2 I present the discussion here in terms of the classical theory's ontology, where degrees (type $d$, elements of $D_{d}$ ) are points on the degree scale and what I call an interval is a set of points, type $\langle d, t\rangle$. 
Quantifiers in than-clauses

below).

(25) Joe is taller than exactly 5 people are.

Here is a rough sketch of Schwarzschild \& Wilkinson's analysis of this example.

(26) Subord: $\quad[\lambda D$. exactly 5 people's height falls within $D]$

Matrix + Comp: $\max D^{\prime}:\left[\right.$ Joe's height $\left.-D^{\prime}\right] \neq 0$

the largest interval some distance below Joe's height

Whole clause: the largest interval some distance below Joe's height is an interval into which exactly 5 people's height falls.

Note that the quantifier is not given wide scope over the comparison at all under this analysis. The interval idea allows us to interpret it within the than-clause. While solving the puzzle of apparent wide scope operators, the analysis makes wrong predictions for apparent narrow scope quantifiers (cf. example (27)). The available reading cannot be accounted for ((28a) is the semantics predicted by the classical analysis, corresponding to the intuitively available reading; (28b) is the semantics that the Schwarzschild \& Wilkinson analysis predicts).

(27) John is taller than anyone else is.

(28) a. John's height $>\max (\lambda d . \exists x[x \neq$ John $\& x$ is $d$-tall $])$

b. \#The largest interval some distance below John's height is an interval into which someone else's height falls = Someone is shorter than John.

The breakthrough achieved by this analysis is that we can assign to the thanclause a useful semantics while interpreting the quantifier inside that clause. For this reason, the interval idea is to my mind a very important innovation. The analysis still has a crucial problem in that it does not extend to the apparent narrow scope quantifiers. That is, it fails in precisely those cases that were unproblematic for the classical analysis. I will also mention that the semantics of comparison becomes rather complex under this analysis, since the comparative itself compares intervals. This is not in line with the plot I outlined above of maintaining as the semantics of the comparative operator the plain 'larger than'-relation. 
Sigrid Beck

\subsubsection{Heim 2006b}

Heim (2006b) adopts the interval analysis, but combines it with a scope mechanism that derives ultimately a wide and a narrow scope reading of a quantifier relative to a comparison. Her analysis extends proposals by Larson (1988). Larson's own analysis is only applicable to than-clauses with an adjective phrase gap denoting a property of individuals - a limitation remedied by Heim. Let us consider her analysis of apparent wide scope of quantifier data, like (29), first. Heim's LF for the sentence is given in (30). She employs an operator Pi (Point to Interval, credited to Schwarzschild (2004)), whose semantics is specified in (31). Compositional interpretation (once more somewhat simplified for the matrix clause, for convenience) is given in (32).

(29) John is taller than every girl is.

(30) [IP [CP than [1 [every girl [2 [AP [Pi $\left.\mathrm{t}_{1}\right]\left[3\left[_{\mathrm{AP}} \mathrm{t}_{2}\right.\right.$ is $\mathrm{t}_{3}$ tall]]]]]]] [IP 4 [[-er $\mathrm{t}_{4}$ ] [5 [John is $\mathrm{t}_{5}$ tall]]]]

(31) $\llbracket \mathrm{Pi} \rrbracket=\lambda D \cdot \lambda P . \max (P) \in D$

(32) a. main clause:

$\left[\left[\left[4\left[\left[-\mathrm{er}_{4}\right]\left[5\left[\mathrm{John}\right.\right.\right.\right.\right.\right.$ is $\mathrm{t}_{5}$ tall]]]]] $=\lambda d$. John is taller than $d$

b. than-clause:

[[than [1 [every girl [2 [AP [ $\left.\mathrm{Pi}_{1}\right]$ [3 [AP $\mathrm{t}_{2}$ is $\mathrm{t}_{3}$ tall]]]]]]]]= $\lambda D^{\prime}$. $\llbracket$ [every girl [2 [AP [Pi t $\left.\mathrm{A}_{1}\right]\left[3\left[{ }_{\mathrm{AP}} \mathrm{t}_{2}\right.\right.$ is $\mathrm{t}_{3}$ tall] $\left.\left.\left.\left.\left.]\right]\right]\right]\right]\right] \rrbracket^{g^{D^{\prime} / 1}}=$ $\lambda D^{\prime} . \forall x\left[\operatorname{girl}(x) \rightarrow \llbracket\left[\left[_{\mathrm{AP}}\left[\mathrm{Pi} \mathrm{t}_{1}\right]\left[3\left[{ }_{\mathrm{AP}} \mathrm{t}_{2} \text { is } \mathrm{t}_{3} \text { tall] }\right]\right]\right]^{g^{D^{\prime} / 1^{x / 2}}}\right]=\right.$ $\left.\lambda D^{\prime} . \forall x\left[\operatorname{girl}(x) \rightarrow[\lambda D . \lambda P . \max (P) \in D]\left(D^{\prime}\right)\left(\llbracket\left[3\left[\mathrm{t}_{2} \text { is } \mathrm{t}_{3} \text { tall }\right]\right]\right]^{g^{x / 2}}\right)\right]=$

$\lambda D^{\prime} . \forall x\left[\operatorname{girl}(x) \rightarrow[\lambda D . \lambda P . \max (P) \in D]\left(D^{\prime}\right)(\lambda d\right.$. Height $(x) \geq$ d) $]=$

$\lambda D^{\prime} . \forall x\left[\operatorname{girl}(x) \rightarrow \max (\lambda d\right.$. Height $\left.(x) \geq d) \in D^{\prime}\right]=$

$\lambda D^{\prime} . \forall x\left[\operatorname{girl}(x) \rightarrow \operatorname{Height}(x) \in D^{\prime}\right]$

intervals into which the height of every girl falls

c. main clause + than-clause:

$\llbracket(29) \rrbracket=$

$\left[\lambda D^{\prime} . \forall x\left[\operatorname{girl}(x) \rightarrow \operatorname{Height}(x) \in D^{\prime}\right]\right](\lambda d$. John is taller than $d)=$

$\forall x[\operatorname{girl}(x) \rightarrow \operatorname{Height}(x) \in(\lambda d$. John is taller than $d)]=$ for every girl $x$ : John is taller than $x$ 
The than-clause provides intervals into which the height of every girl falls. The whole sentence says that the degrees exceeded by John's height is such an interval. Semantic reconstruction (i.e. lambda conversion) simplifies the whole to the claim intuitively made, that every girl is shorter than John. The analysis assumes that the denotation domain $\mathrm{D}_{d}$ is a set of degree 'points', and that intervals are of type $\mathrm{D}_{\langle d, t\rangle}$.

The analysis is a way of interpreting the quantifier inside the than-clause, and deriving the apparent wide scope reading over the comparison through giving the quantifier scope over the shift from degrees to intervals (the Pi operator). It is applicable to other kinds of quantificational elements like intensional verbs in the same way. Our example with predict is analysed below; the intuitively plausible reading can now be derived straightforwardly from the LF in (34).

(33) a. John is taller than I had predicted (that he would be).

b. $\forall w[w R @ \rightarrow \max (\lambda d$. John is $d$-tall in @ $)>$

$\max (\lambda d$. John is $d$-tall in $w)$ ]

= For every world compatible with my predictions:

John's actual height exceeds John's height in that world.

(34) [IP [CP than [1 [I had predicted [CP [Pi t $\left.\mathrm{P}_{1}\right]$ [2 [AP John $\mathrm{t}_{2}$ tall]]]]]]]

[IP 3 [John is taller than $t_{3}$ ]]]

(35) a. main clause:

$\llbracket\left[3\left[\mathrm{John}\right.\right.$ is taller than $\left.\left.\mathrm{t}_{3}\right]\right] \rrbracket=(\lambda d$. John is taller than $d$ in @ $)$

b. than-clause:

【[than [1 [I had predicted [CP [Pi t $\left.{ }_{1}\right]$ [2 [AP John $\mathrm{t}_{2}$ tall]]]]]]]] = $\left[\lambda D^{\prime} . \forall w\left[w R @ \rightarrow \llbracket\left[{ }_{\mathrm{CP}}\left[\mathrm{Pi} \mathrm{t}_{1}\right]\left[2\left[{ }_{\mathrm{AP}} \mathrm{John} \mathrm{t}_{2} \text { tall }\right]\right]\right]\right]^{\left.g^{\left[D^{\prime}\right.} / 1\right]}\right]=$

$\left[\lambda D^{\prime} . \forall w\left[w R @ \max (\lambda d\right.\right.$. Height $($ John $\left.\left.)(w) \geq d) \in D^{\prime}\right]\right]=$ $\left[\lambda D^{\prime} . \forall w\left[w R @ \operatorname{Height}(\mathrm{John})(w) \in D^{\prime}\right]\right]$

intervals into which John's height falls in all my predictions

c. main clause + than-clause:

$\llbracket(34) \rrbracket=$

$\left[\lambda D^{\prime} . \forall w\left[w R @ \operatorname{Height}(\mathrm{John})(w) \in D^{\prime}\right]\right]$

$(\lambda d . J$ is taller than $d$ in @)

= for every $w$ compatible with my predictions:

John's actual height exceeds John's height in $w$.

The effect of the Pi operator on the predicate of degrees it combines with is sketched below for the AP tall. As long as a than-clause quantifier takes 
scope over the Pi operator, the resulting meaning of the whole sentence will be one that lets the quantifier take scope over the comparison, even though it is interpreted syntactically below the comparative operator and inside the than-clause.

(36) Pi shifts from degrees to intervals:

$[\lambda d$. Height $(x) \geq d] \Longrightarrow[\lambda D$. Height $(x) \in D]$

In contrast to Schwarzschild \& Wilkinson's original interval analysis, Heim is able to derive apparently narrow scope readings of an operator relative to the comparison as well. The sentence in (37a) is associated with the LF in (38). Note that here, the shifter takes scope over the operator have to. This makes have to combine with the degree semantics in the original, desired way, giving us the minimum compliance height (just like it did before, without the intervals). The shift is essentially harmless.

(37) a. Mary is taller than she has to be.

b. $\max (\lambda d$. Mary is $d$-tall in @ $)$

$>\max (\lambda d . \forall w[w R @ \rightarrow$ Mary is $d$-tall in $w])$

Mary's actual height exceeds the degree of tallness which she has in all worlds compatible with the school rules;

i.e. Mary's actual height exceeds the required minimum, $1.70 \mathrm{~m}$.

(38) [IP [CP than [1 [[[Pi t 1$]$ [2 [has-to [Mary $t_{2}$ tall]]]]]]]

[IP 3 [Mary is taller than $t_{3}$ ]]]

(39) a. main clause:

$\llbracket\left[3\right.$ [Mary is taller than $\left.\left.\left.t_{3}\right]\right]\right] \rrbracket=(\lambda d$. Mary is taller than $d$ in @ $)$

b. than-clause:

[[than [1 [[[Pi t 1 ] [2 [has-to [Mary $\mathrm{t}_{2}$ tall]]]]]]』=

$\lambda D^{\prime}$. $\llbracket\left[\left[\mathrm{Pi} \mathrm{t}_{1}\right]\left[2\right.\right.$ [has-to [Mary $\mathrm{t}_{2}$ tall] $\left.\left.\left.\left.]\right]\right]\right]\right] \rrbracket^{g^{\left[D^{\prime} / 1\right]}=}$

$\lambda D^{\prime} . \max \left(\lambda d\right.$. $\llbracket$ has-to [Mary $\mathrm{t}_{2}$ tall]] $\left.\left.\left.]\right]\right] \rrbracket^{g[d / 2]}\right) \in D^{\prime}$

$\lambda D^{\prime} . \max (\lambda d . \forall w[w R @ \rightarrow$ Mary is $d$-tall in $w]) \in D^{\prime}$

intervals into which the required minimum falls

c. main clause + than-clause:

$\llbracket(38) \rrbracket=$

$\left[\lambda D^{\prime} . \max (\lambda d . \forall w[w R @ \rightarrow\right.$ Mary is $d$-tall in $\left.w]) \in D^{\prime}\right]$

( $\lambda d$. Mary is taller than $d$ in @)

= Mary is taller than the required minimum. 
Quantifiers in than-clauses

Other apparent narrow scope operators receive a parallel analysis. The crucial ingredient to this analysis is that the Pi operator is a scope bearing element, able to take local or non-local scope. Pi-phrase scope interaction is summarized below:

(40) Pi takes narrow scope relative to quantifier

$\Longrightarrow$ apparent wide scope reading of quantifier over comparison

Pi takes wide scope relative to quantifier

$\Longrightarrow$ apparent narrow scope reading of quantifier relative to comparison

Thus than-clauses include a shift from degrees to intervals, which allows us to assign a denotation to the than-clause with the quantifier. The shift amounts to a form of type raising. Through semantic reconstruction, the matrix clause is interpreted in the scope of a than-clause operator when that operator has scope over the shifter. In contrast to Schwarzschild \& Wilkinson, comparison is ultimately between degrees, not intervals.

Heim's analysis is able to derive both wide and narrow scope readings of operators in than-clauses. It does so without violating syntactic constraints. There is, however, an unresolved question: when do we get which reading? How could one constrain Pi-phrase/operator interaction in the desired way? One place where this problem surfaces is once more negation, where we expect an LF that would generate an acceptable wide scope of negation reading. That is, the $L F$ in (41b) should be grammatical and hence (41a) should be acceptable on the reading derived from this LF in (42).

(41) a. *John is taller than no girl is.

b. [IP [CP than [1 [no girl [2 [[Pi $\left.\mathrm{t}_{1}\right]\left[3\left[\mathrm{t}_{2}\right.\right.$ is $\mathrm{t}_{3}$ tall] $\left.\left.\left.\left.\left.]\right]\right]\right]\right]\right]$ [IP 4 [[-er $t_{4}$ ] [5 [John is $t_{5}$ tall]]]]

(42) a. main clause:

$\llbracket\left[4\right.$ [[-er $\left.\mathrm{t}_{4}\right]\left[5\right.$ [John is $\mathrm{t}_{5}$ tall] $\left.]\right] \rrbracket=\lambda d$. John is taller than $d$

b. than-clause:

『[than [1 [no girl [2 [[Pi t $\left.\mathrm{t}_{1}\right]\left[3\left[\mathrm{t}_{2}\right.\right.$ is $\mathrm{t}_{3}$ tall] $\left.\left.\left.\left.\left.]\right]\right]\right]\right]\right] \rrbracket=$

$\lambda D^{\prime}$. for no girl $x: \max (\lambda d . x$ is $d$-tall $) \in D^{\prime}$

intervals into which the height of no girl falls

c. main clause + than-clause:

$\llbracket(4 \mathrm{lb}) \rrbracket=$

$\left[\lambda D^{\prime}\right.$. for no girl $x: \max (\lambda d . x$ is $d$-tall $\left.) \in D^{\prime}\right](\lambda d . J$ is taller than $d)$

$=$ for no girl $x$ : John is taller than $x$ 
Adopting the interval analysis, but combining it with a scope mechanism and semantic reconstruction, allows Heim to derive both types of readings (apparent narrow and apparent wide scope), and to reduce the comparison ultimately back to a comparison between degrees. Thus her empirical coverage is greater and the semantics of comparison simpler than Schwarzschild \& Wilkinson's analysis. The problem that this analysis faces is overgeneration. We do not have an obvious way of predicting when we get which reading. The fact that in general, only one scope possibility is available makes one doubt that this is really a case of systematic scope ambiguity.

\subsection{Alternative new analyses: Gajewski, van Rooij, Schwarzschild}

There is a group of new proposals - Gajewski 2008, van Rooij 2008 and Schwarzschild 2008 - for how to deal with quantifiers in than-clauses whose approach seems to be inspired by Heim's (2006b) analysis. I present below a simplified version of this family of approaches that is not entirely faithful to any of them. I call this the NOT-theory. It can be summarized in relation to the previous subsection as 'keep the than-clause internal operator, but not the intervals'. It adopts the idea that there is an operator - like Heim's $\mathrm{Pi}$ - that can take wide or narrow scope relative to a than-clause quantifier, dictating what kind of reading the comparative sentence receives. It does not adopt an interval analysis, and thus the operator is not Pi and the semantics of the comparative is not the classical one. Instead, the operator is negation and the proposed semantics is basically Seuren's (1978).

\subsubsection{Seuren's semantics for the comparative (operator: NOT)}

Seuren (1978) suggests (43b) as the interpretation of (43a). The than-clause provides the set of degrees of tallness that Bill does not reach. It does so by virtue of containing a negation, as illustrated in the LF in (44). This meaning could be combined intersectively with the main clause and the degree existentially bound, as represented in (45).

(43) a. John is taller than Bill is.

b. $\exists d[\operatorname{Height}(J) \geq d \& \neg \operatorname{Height}(B) \geq d]$

c. There is a degree of tallness that John reaches and Bill doesn't reach. 
Quantifiers in than-clauses

(44) a. than $\lambda d$ [NOT Bill is $d$-tall]

b. $\lambda d[\neg \operatorname{Height}(B) \geq d]=\lambda d[\operatorname{Height}(B)<d]$

(45) $\quad[\exists[\lambda d$ [John is $d$-tall] [than $\lambda d$ [NOT Bill is $d$-tall]]]

The authors mentioned above note that this semantics gives us an easy way to derive the intuitively correct interpretation for apparent wide scope quantifiers. This is illustrated below for the universal NP. In (46) I show that the desired meaning is easily described in this analysis and in (47) I provide the LF for the than-clause that derives it. (48) illustrates that some, another apparent wide scope quantifier, is equally unproblematic.

(46) a. John is taller than every girl is.

b. $\exists d[\operatorname{Height}(J) \geq d \& \forall x[\operatorname{girl}(x) \rightarrow \operatorname{Height}(x)<d]]$

c. every girl is shorter than John.

(47) a. than every girl is

b. than $\lambda d$ [every girl [1 [NOT [ $t_{1}$ is $d$ tall]]]]

c. than $\lambda d . \forall x[\operatorname{girl}(x) \rightarrow \operatorname{Height}(x)<d]]$

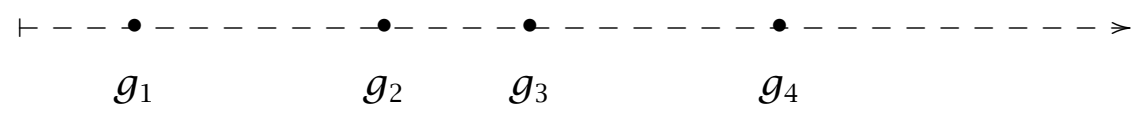

(48) a. John is taller than some girl is.

b. $\exists d[\operatorname{Height}(J) \geq d \& \exists x[\operatorname{girl}(x) \& \operatorname{Height}(x)<d]]$

c. there is a girl who is shorter than John.

An interesting application is negation, here illustrated with the negative quantifier no. Proceeding in the now familiar way, we derive (49b). Rephrasing this in terms of (49c) makes it clear that the resulting semantics is very weak. Whenever the girls have any measurable height at all - that is, whenever the than-clause can be appropriately used - there will be a height degree that John reaches and that all the girls reach as well. The smallest degree on the scale will be such a degree. The NOT-theory proposes that the sentence is unacceptable because it is necessarily uninformative.

(49) a. *John is taller than no girl is.

b. $\exists d[\operatorname{Height}(J) \geq d \&$ for no girl $x$ : Height $(x)<d]$

c. $\exists d[\operatorname{Height}(J) \geq d \&$ for every $\operatorname{girl} x$ : $\operatorname{Height}(x) \geq d]$

uninformative!

(The lowest degree on the height scale makes this true.) 
Sigrid Beck

\subsubsection{NOT has to take varying scope}

The NOT-theory needs another important ingredient: Just like the Pi-operator above, other than-clause internal operators have to take flexible scope relative to NOT in order to create the different readings we observe. This is illustrated below with the familiar have to example, and with allowed.

(50) a. Mary is taller than she has to be.

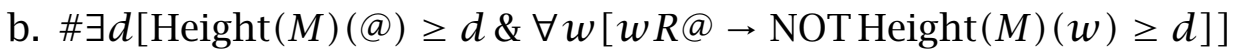

Mary should have been shorter than she is.

c. $\exists d[\operatorname{Height}(M)(@) \geq d \& \operatorname{NOT} \forall w[w R @ \rightarrow \operatorname{Height}(M)(w) \geq d]]$

Mary is taller than the minimally required height.

(51) a. John is taller than he is allowed to be.

b. \# $\exists d[\operatorname{Height}(J)(@) \geq d \& \exists w[w R @ \& \operatorname{NOT} \operatorname{Height}(J)(w) \geq d]]$

$\exists d[\operatorname{Height}(J)(@) \geq d \& \exists w[w R @ \& \operatorname{Height}(J)(w)<d]]$

John would have been allowed to be shorter than he is.

c. $\exists d[\operatorname{Height}(J)(@) \geq d \& \operatorname{NOT} \exists w[w R @ \& \operatorname{Height}(J)(w) \geq d]]$

John is taller than the tallest permissible height.

(52) a. \#than $\lambda d$ [allowed [ $\lambda w$ [NOT [John is $d$ tall in $w$ ]]]]

b. than $\lambda d$ [NOT [allowed [ $\lambda w$ [John is $d$ tall in $w$ ]]]]

Just like the Pi-theory, then, the NOT-theory is able to generate the range of readings we observe for operators in than-clauses. It seems somewhat simpler than the Pi-theory in that it does not take recourse to intervals in addition to a scopally flexible than-clause internal operator. But as in the case of the Pi-theory, we must next ask ourselves what prevents the unavailable readings, e.g. what excludes the LF in (52a).

\subsubsection{Which reading?}

The NOT-theory would have an empirical advantage over the Pi-theory if constraints on scope could be found to deal with the overgeneration problem we noted above. A first successful application are polarity items. Example (53a) can only have the LF in (54b), not the one in (54a), according to constraints on the distribution of NPIs. Thus we only derive the approproate interpretation. Note though that the Pi-theory has the same success since the scope of Pi is a downward entailing environment, but the rest of the than-clause isn't (compare Heim 2006b). (55) is the mirror image. 
Quantifiers in than-clauses

(53) a. John is taller than any girl is.

b. $\# \exists d[\operatorname{Height}(J) \geq d \& \exists x[\operatorname{girl}(x) \& \operatorname{Height}(x)<d]]$ there is a girl who is shorter than John.

c. $\exists d[\operatorname{Height}(J) \geq d \& \operatorname{NOT} \exists x[\operatorname{girl}(x) \& \operatorname{Height}(x) \geq d]]$ John reaches a height degree that no girl reaches. $=$ John is taller than every girl.

(54) a. *than $\lambda d$ [any girl [ 1 [NOT [ $\mathrm{t}_{1}$ is $d$ tall]]]]

b. than $\lambda d$ [NOT [any girl [ $1 \mathrm{t}_{1}$ is $d$ tall]]]]

(55) John is taller than some girl is.

Let us next reexamine negation. Two interpretations need to be considered. The one in (56b) was already rejected above as uninformative. It turns out that the alternative interpretation is equally uninformative. The ungrammaticality of negation in than-clauses is thus captured elegantly by this theory. Here it has an advantage over the Pi-theory.

a. *John is taller than no girl is.

b. $\exists d[\operatorname{Height}(J) \geq d \&$ for no girl $x$ : Height $(x)<d]$ uninformative

c. $\exists d[\operatorname{Height}(J) \geq d \&$ NOT for no girl $x$ : Height $(x) \geq d]$ uninformative $=\exists d[\operatorname{Height}(J) \geq d \&$ some girl $x$ : Height $(x) \geq d]$

Among the proponents of the NOT-theory, Schwarzschild (2008) examines modals. He argues that the NOT-theory predicts that modals in than-clauses should give rise to the same reading that they have with ordinary clause-mate negation. This prediction is borne out, as the examples below illustrate.

(57) a. John is not allowed to be that tall.

NOT $\gg$ allowed

b. than he is allowed to be.

(58) a. John might not be that tall.

might $\gg$ NOT

b. than he might be.

(59) a. John is not supposed to be that tall. supposed $\gg$ NOT

b. than he is supposed to be.

(6o) a. John is not required to be that tall. $\quad$ NOT $\gg$ required

b. than he is required to be.

While this is helpful with modals, it stops short of explaining the interpretation associated with intensional full verbs like predict. 
Sigrid Beck

a. John was not predicted to be that tall. $\quad$ NOT $\gg$ predict - \#

b. than he was predicted to be.

Two further possible constraints are discussed. Van Rooij (2008) examines universal DPs and Gajewski (2008) investigates numeral DPs. Let us consider both in turn.

Note first that a universal DP is ambiguous relative to clause mate negation. In particular it allows a reading in which the universal takes narrow scope relative to negation. Thus there are no inherent scope constraints that would help us to exclude $\left(63^{\prime} b\right)$ as an LF of (63a). But exclude it we must, since it gives rise to the unavailable reading (63c).
a. Every girl isn't that tall.
ambiguous

b. than every girl is.

(63) a. John is taller than every girl is.

b. $\exists d[\operatorname{Height}(J) \geq d \& \forall x[\operatorname{girl}(x) \rightarrow \operatorname{Height}(x)<d]]$

'Every girl is shorter than John.'

c. $\# \exists d[\operatorname{Height}(J) \geq d \&$ NOT $\forall x[\operatorname{girl}(x) \rightarrow \operatorname{Height}(x) \geq d]]$

'John reaches a height that some girl doesn't.'

$=$ John is taller than the shortest girl.

$\left(63^{\prime}\right) \quad$ a. than $\lambda d$ [every girl [1 [NOT [ $\mathrm{t}_{1}$ is $\mathrm{d}$ tall]]]]

b. *than $\lambda d$ [NOT [every girl [ 1 [ $\mathrm{t}_{1}$ is $d$ tall]]]]

Van Rooij observes that (63'a) yields stronger truth conditions than $\left(63^{\prime} b\right)$. He proposes that if no independent constraint excludes one of the LFs, you have to pick the one that results in the stronger truth conditions. This amounts to the suggestion that than-clauses fall within the realm of application of the Strongest Meaning Hypothesis (SMH; Dalrymple, Kanazawa, Kim, Mchombo \& Peters 1998). If they do, the NOT-theory can make the desired predictions about every DPs (and some other relevant examples). So could the Pi-theory, though, so this does not distinguish between the two scope based theories of quantifiers in than-clauses.

While I am sympathetic to the idea of extending application of the SMH, I see some open questions for doing so in the case of than-clauses. Dalrymple et al. originally proposed the SMH to deal with the interpretation of reciprocals. (64a) receives a stronger interpretation than (64b), for example, because the predicate to stare at makes it factually impossible for the reading of (64a) to ever be true. Similarly for (64c) vs. (64a,b). But (64a) only has one inter- 
Quantifiers in than-clauses

pretation, the strongest one, and $(64 \mathrm{~b})$ also cannot have a reading parallel to (64c). The SMH says, very roughly, that out of the set of theoretically possible interpretations you choose the strongest one that has a chance of resulting in a true statement, i.e. that is conceptually possible. ${ }^{3}$

(64) a. These three people know each other. = everyone knows everyone else.

b. These three people were staring at each other. = everyone was staring at someone else.

c. These three people followed each other into the elevator. = everyone followed, or was followed by, someone else.

There is a theoretical question as to when the SMH applies. We would not wish it to apply in (62) for instance because it would predict that there is no ambiguity. When there is ambiguity, the data in question must not be subject to the SMH. Are than-clauses in the domain of application of the SMH? Prima facie, this seems very plausible, because - just like reciprocals - they are (almost always) unambiguous, while semantic theory provides several potential interpretations. What strikes me as problematic is that there is no way to make the weaker reading emerge, even if the stronger reading is conceptually impossible. The following sentences are necessarily false, rather than having the interpretations indicated.

$\left(64^{\prime}\right) \quad$ a. (about a $100 \mathrm{~m}$ race:)

The next to last finalist was faster than every other finalist.

$\neq$ the next to last finalist was faster than the slowest other finalist.

3 Below I provide the formulation of the SMH given in Beck 2001. If we extend the domain of application of the SMH to than-clauses, we need to strike out those phrases that make explicit reference to reciprocals, as indicated. The relevant point is that the SMH makes reference to interpretations compatible with non-linguistic information $I$, which in the examples in $\left(64^{\prime}\right)$ below would be knowledge about the order of finalists, elevator buttons and weekdays, parallel to knowledge about processions of people and possibilities for staring in (64).

(i) Strongest Meaning Hypothesis (SMH)

Let $S_{r}$ be the set of theoretically possible reciprecal interpretations for a sentence $\mathrm{S}$. Then, $\mathrm{S}$ can be uttered felicitously in a context $c$, which supplies non-linguistic information $I$ relevant to the reciprecal's interpretation, provided that the set $S_{c}$ has a member that entails every other one.

$S_{c}=\left\{p: p\right.$ is consistent with $I$ and $\left.p \in S_{r}\right\}$

In that case, the use of $\mathrm{S}$ in $c$ expresses the logically strongest proposition in $S_{c}$. 
Sigrid Beck

b. (in an elevator:)

The second button from the bottom is higher than every other button.

₹ the second button from the bottom is higher than the lowest other button.

c. Friday is earlier than every other day of the week. $\neq$ Friday is earlier than the latest other day of the week.

Thus than-clauses do not seem parallel to reciprocals. It would be better if an LF that gives rise to the 'the least ... other' reading for universal DPs simply did not exist.

Turning now to numeral DPs, note first that it is not immediately obvious how the NOT-theory predicts a plausible meaning for them at all. Gajewski (2008) points out that the following analysis of exactly-DPs gives rise to truth conditions that are too weak. $\left(65^{\prime}\right)$ would be true in a situation in which more than three girls stay below John's height.

(65) John is taller than exactly three girls are.

$\left(65^{\prime}\right) \quad \exists d[\operatorname{Height}(J) \geq d \&$ for exactly 3 girls $x$ : Height $(x)<d]$

At least three girls are below John's height

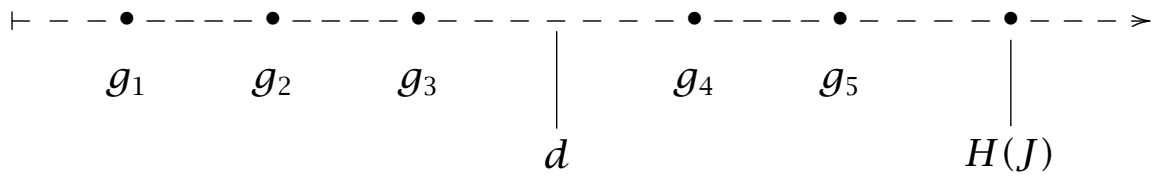

Reversing the scope of NOT and the exactly-DP doesn't help:

$\left(65^{\prime \prime}\right) \quad \exists d[\operatorname{Height}(J) \geq d \&$ NOT for exactly 3 girls $x$ : Height $(x) \geq d]$

there is a degree of height that John reaches that is not reached by exactly 3 girls,

i.e. fewer or more girls reach that degree

true e.g. if John is taller than every one of five girls

Gajewski develops an analysis that relies on Krifka's (1999) work on exactly, at least and at most, according to which these elements take effect at the level of the utterance, far away from their surface position. I present this analysis in simplified terms below, using (66) to illustrate. The semantic effect of exactly is due to an operator I call EXACT, which applies at the utterance level and operates on the basis of the ordinary as well as the focus semantic 
Quantifiers in than-clauses

value of its argument. The operator's semantics is given in (67). The truth conditions derived for the example are the right ones, as shown in (68) ((68) uses Link's (1983) operator $*$ for pluralization of the noun).

(66) a. Exactly three girls weigh $50 \mathrm{lb}$.

b. [EXACT [XP (exactly) three $e_{\mathrm{F}}$ girls weigh $\left.\left.50 \mathrm{lb}.\right]\right]$

$\left(66^{\prime}\right) \llbracket$ three girls weigh $50 \mathrm{lb} . \rrbracket_{o}=$ $\exists X[* \operatorname{girl}(X) \& \operatorname{card}(X)=3 \& *$ weigh.5o.lb $(X)]$

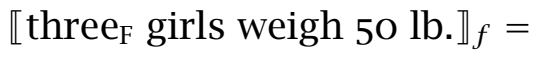
$\{\exists X[* \operatorname{girl}(X) \& \operatorname{card}(X)=n \& *$ weigh.5o.lb $(X)]: n \in N\}$

(67) $\llbracket \mathrm{EXACT} \rrbracket\left(\llbracket \mathrm{XP} \rrbracket_{f}\right)\left(\llbracket \mathrm{XP} \rrbracket_{o}\right)=1$ iff $\llbracket \mathrm{XP} \rrbracket_{o}=1 \& \forall q \in \llbracket \mathrm{XP} \rrbracket_{f}: \neg\left(\llbracket \mathrm{XP} \rrbracket_{o} \rightarrow q\right) \rightarrow \neg q$

'Out of all the alternatives of XP, the most informative true one is the ordinary semantics of XP.'

(68) $\llbracket(66 b) \rrbracket=1$ iff

$\exists X[* \operatorname{girl}(X) \& \operatorname{card}(X)=3 \& *$ weigh.50.lb $(X)] \&$

$\forall n[n>3 \rightarrow \neg \exists X[* \operatorname{girl}(X) \& \operatorname{card}(X)=n \& *$ weigh.5o.lb $(X)]]$ iff $\max (\lambda n . \exists X[* \operatorname{girl}(X) \& \operatorname{card}(X)=n \& *$ weigh.5o.lb $(X)])=3$

Krifka's analysis of exactly allows us to assign the problematic example (65) the LF in (69), which captures the right meaning, namely the interpretation in $\left(69^{\prime}\right)$.

(69) EXACT [ $\exists\left[\lambda d\right.$ [John is $d$-tall] [than $\lambda d$ [three $_{\mathrm{F}}$ girls [ $\lambda x$ [NOT $x$ is $d$-tall]]]]

$\left(69^{\prime}\right) \quad \max (\lambda n . \exists d[\operatorname{Height}(J) \geq d \&$ for $n$ girls $x$ : Height $(x)<d])$ the largest number $n$ such that John reaches a height that $n$ girls don't is 3. = exactly three girls are shorter than John.

Thus independently motivated assumptions about numerals allow the NOTtheory to derive the desired interpretation. However, there is still the question of the other LF, (70), in which NOT takes scope over the DP. This gives rise to interpretation $\left(7 \mathrm{O}^{\prime}\right)$.

(70) EXACT [ $\exists\left[\lambda d\right.$ [John is $d$-tall] [than $\lambda d$ [NOT three ${ }_{\mathrm{F}}$ girls $[\lambda x[x$ is $d$-tall]]]]

$\left(7 \mathrm{O}^{\prime}\right) \quad \max (\lambda n \cdot \exists d[\operatorname{Height}(J) \geq d \&$ NOT for $n$ girls $x$ : Height $(x) \geq d])$ the largest number $n$ such that there is a height John reaches and it's 
not the case that $n$ girls do is 3 .

$=$ exactly two girls are shorter than John.

The reasoning in (71) makes it clear that this reading leads to truth conditions that do not correspond to an available reading; they would make the sentence true in the situation depicted, where there are two girls shorter than John.
a. $\exists d[\operatorname{Height}(J) \geq d \&$ NOT for $n$ girls $x$ : Height $(x) \geq d]$ $=\exists d[\operatorname{Height}(J) \geq d \&$ fewer than $n$ girls reach $d]$
b. $\exists d[\operatorname{Height}(J) \geq d \&$ fewer than 3 girls reach $d]$

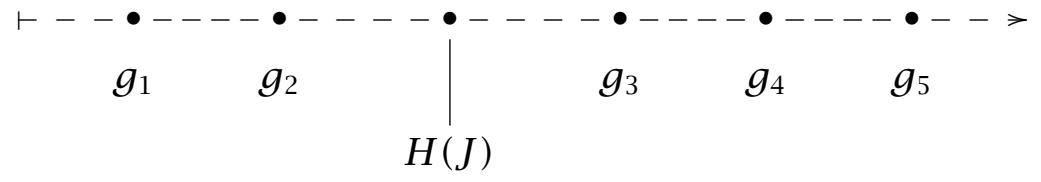

The NOT-theory would have to come up with an explanation for why this reading is unavailable. I am not aware that there is at present such an explanation. Note that even if we didn't have the reservations about the SMH pointed out above, it would not apply here, as the two interpretations don't stand in an entailment relation.

To summarize: just like the Pi-theory, the NOT-theory faces an overgeneration problem. Both the Pi-theory and the NOT-theory solve this easily regarding NPIs. The NOT-theory also has a simple story about modals and negative quantifiers. It does not have an explanation for intensional full verbs and numeral DPs, and I argue it does not have a story about universal DPs (or other prospective applications of the SMH) either. Thus I see some progress compared to the Pi-theory, but not a complete analysis. A conceptual advantage seems to be the NOT-theory's simplicity. But we will need to reexamine that in the next subsection.

\subsubsection{Reference to degrees - differentials}

One of the strengths of the classical analysis of comparatives is the way in which it deals with explicit reference to degrees. For example differentials in comparatives, illustrated in (72) and (73), receive an easy and natural analysis.

(72) a. Bill is $1.70 \mathrm{~m}$ tall.

b. John is $2^{\prime \prime}$ taller than that.

c. Height $(J) \geq 2^{\prime \prime}+1.70 m$ 
Quantifiers in than-clauses

(73) a. John is $2^{\prime \prime}$ taller than Bill is.

b. Height $(J) \geq 2^{\prime \prime}+\max (\lambda d$. Height $(B) \geq d)$

$=\operatorname{Height}(J) \geq 2^{\prime \prime}+\operatorname{Height}(B)$

It is not obvious how to incorporate differentials into the NOT-theory, whose semantics of a simple example is repeated in (74). That is because the than-clause does not refer to a degree.

(74) a. John is taller than Bill is.

b. $\exists d[\operatorname{Height}(J) \geq d \& \operatorname{NOT} \operatorname{Height}(B) \geq d]$

Among the proponents of the NOT-theory, Schwarzschild (2008) discusses this problem. He proposes to understand (75a) in terms of (75b); I simplify this to $(75 \mathrm{c})$ for the purposes of discussion.

(75) a. John is $2^{\prime \prime}$ taller than Bill is.

b. $\exists d\left[\operatorname{Height}(J) \geq d \& 2^{\prime \prime}\left(\lambda d^{\prime} . d^{\prime} \leq d \& \operatorname{Height}(B)<d^{\prime}\right)\right]$

c. $\left.\left.\quad 2^{\prime \prime}\left(\lambda d^{\prime} . d^{\prime} \leq \operatorname{Height}(J) \& \operatorname{Height}(B)<d^{\prime}\right)\right]\right)$

"the degrees between Bill's height and John's are a 2 " interval"

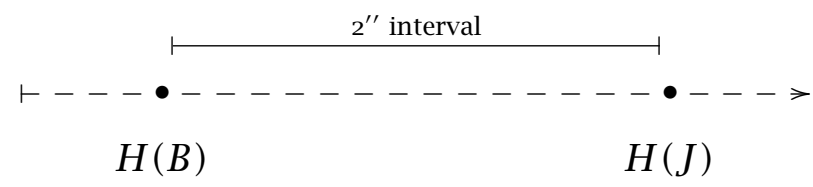

The question is how to derive this interpretation. Schwarzschild proposes to replace NOT in the than-clause with an operator FALL-SHORT. The resulting LF of our example is given in $\left(75^{\prime}\right.$ a) and the semantics of FALL-SHORT in $\left(75^{\prime} \mathrm{b}\right)$. Diff is a variable that is the first argument of FALL-SHORT, to be bound outside the than-clause and identified with the differential in the matrix clause (as if the differential was raised out of the embedded clause to its main clause position).

$\left(75^{\prime}\right) \quad$ a. than [[FALL-SHORT Diff] $\lambda d$ [Bill is $d$-tall]]

b. FALL-SHORT $\left.=\lambda \operatorname{Diff} . \lambda D_{\langle} d, t\right\rangle . \lambda d$. Diff $\left(\lambda d^{\prime} . d^{\prime} \leq d \& D\left(d^{\prime}\right)=0\right)$

c. $\operatorname{Diff}\left(\lambda d^{\prime} . d^{\prime} \leq d \& \operatorname{Height}(B)<d^{\prime}\right)$

Bill's Height is a Diff-large distance below $d$

We combine with the differential next, as shown in (76). Then, the degree $d$ is bound and the usual semantic mechanisms combine this with the rest of the main clause in (77). This derives (75). 
(76) a. $\left[2^{\prime \prime}\right.$ er] [ $\lambda$ Diff [than Bill is tall]]

b. $\left.\quad \lambda d \cdot 2^{\prime \prime}\left(\lambda d^{\prime} . d^{\prime} \leq d \& \operatorname{Height}(B)<d^{\prime}\right)\right]$

Bill's Height is a $2^{\prime \prime}$ distance below $d$

(77) $\quad\left[\exists\left[\lambda d\right.\right.$ [John is $d$-tall] [ $2^{\prime \prime}$ er] [ $\lambda$ Diff [than Bill is tall]]]

It seems to me that this is a rather substantial modification of the original NOT-theory. The basic points about than-clause scope interaction remain the same (as the reader may verify), but some of the explanation is less obvious. In particular, I don't see that scopal behaviour of a modal with same clause negation necessarily predicts scopal behaviour relative to FALL-SHORT, any more than it predicts scopal behaviour relative to Pi. I also believe that we lose the explanation of the unacceptability of negative quantifiers. Neither of the readings associated with the two possible LFs below is necessarily uninformative. Finally, I no longer see that the FALL-SHORT-theory is simpler than the Pi-theory.

(78) a. John is $2^{\prime \prime}$ taller than no girl is.

b. $\quad\left[\exists\left[\lambda d\left[\mathrm{~J}\right.\right.\right.$. is $d$-tall] [ $2^{\prime \prime}$ er] [ $\lambda$ Diff [than [[FALL-SHORT Diff] $\lambda d$ [no girl is $d$-tall]]]

c. $\quad\left[\exists\left[\lambda d\right.\right.$ [J. is $d$-tall] [ $2^{\prime \prime}$ er] [ $\lambda$ Diff [than [no girl $\lambda x$ [FALL-SHORT Diff] $\lambda d$ [ $x$ is $d$-tall] $]]]]$

$\left(78^{\prime}\right) \quad \exists d\left[\operatorname{Height}(J) \geq d \& 2^{\prime \prime}\left(\lambda d^{\prime} . d^{\prime} \leq d \&[\lambda d\right.\right.$. no girl is $d$-tall $\left.\left.\left.]\left(d^{\prime}\right)=0\right)\right]\right]$

$=\exists d\left[\operatorname{Height}(J) \geq d \& 2^{\prime \prime}\left(\lambda d^{\prime} . d^{\prime} \leq d \&\right.\right.$ some girl is $d^{\prime}$-tall $\left.\left.]\right)\right]$

$=\mathrm{John}$ and some girl are at least two inches tall.

$\left(78^{\prime \prime}\right) \quad \exists d\left[\right.$ Height $(J) \geq d \&$ no girl $\left.x: 2^{\prime \prime}\left(\lambda d^{\prime} . d^{\prime} \leq d \& \operatorname{Height}(x)<d^{\prime}\right)\right]$

$=$ no girl is $2^{\prime \prime}$ shorter than John.

I conclude that while the type of analysis discussed in this section - what one might call scopal theories of quantifiers in than-clauses - has brought forth some very interesting ideas, there are also unanswered questions. It may be worthwhile to pursue a scopeless alternative, which is what I will do in the next section.

\section{Analysis: Selection}

The strategy I propose in this section is inspired by both Schwarzschild \& Wilkinson and Heim. Schwarzschild \& Wilkinson's use of intervals is retained in order to be able to interpret a quantifier inside a than-clause. But like Heim, 
Quantifiers in than-clauses

I attempt to make this move compatible with a simple, standard semantics of the comparative. The novel aspect of the analysis below concerns how this is done. I do not adopt a than-clause internal operator Pi and I do not rely on semantic reconstruction. I propose instead that there is a mechanism that derives a particular degree from an interval provided by the than-clause. This degree is compared in the normal way with a matrix clause degree. The trick will be to ensure that the degree chosen is the right one, i.e. that the comparison ultimately made reflects the intuitively accessible reading of the comparative sentence in question. The same selection mechanism will account for both apparent wide scope and apparent narrow scope readings. The analysis will not employ a scoping mechanism that is specific to comparatives. Its relation to the earlier work discussed above can be simply stated as 'keep the intervals, but not the operator'.

Two rationales guide me in pursuing this approach. The first is that a scoping mechanism inside the than-clause overgenerates in ways that we have yet to find the means of constraining. Therefore it would be an advantage to make do without such an extra scopal element. The second is that it remains a strength of the classical analysis that degree operators combine directly with expressions referring to degrees, and that differentials in particular can be accounted for in a direct and straightforward way. Therefore I want to come out of the calculation of the semantics of the than-clause holding in my hand the degree we will be comparing things to. The combination of these two lines of reasoning persuades me to attempt a simplification of Schwarzschild \& Wilkinson, which should of course also cover the apparent narrow scope data that were problematic for them.

Section 3.1 presents the idea behind the selection analysis and applies it to straightforward cases. Apparent narrow scope universals are not straightforward and addressed in Section 3.2. Apparent wide scope existentials similarly seem problematic and are the issue of Section 3.3. In Section 3.4 I reexamine comparatives that combine a differential with a quantifier in the than-clause and propose a refinement of the analysis of the comparative to capture the data.

\subsection{Basic idea and simple cases}

I illustrate the idea behind the selection analysis with example (79), which would not in fact require intervals at all of course. But, suppose that we in general compositionally derive as the meaning of the than-clause a set of 
intervals, as suggested in the Schwarzschild \& Wilkinson and Heim theories. Suppose furthermore that this comes from the basic lexical entry of the adjective, as indicated in (80). This is what I will assume in this section, for the sake of uniformity (see Section 4 for more discussion). It amounts to ( $\left.79^{\prime}\right)$ in the present case. How do I propose to derive the truth conditions of (79a), (79b), from that?

(79) a. John is taller than Bill is.

b. Height (John) $>$ Height(Bill)

$\left(79^{\prime}\right) \quad$ a. $\llbracket[$ than Bill is tall $] \rrbracket=\lambda D^{\prime}$. Height $($ Bill $) \in D^{\prime}$

b.

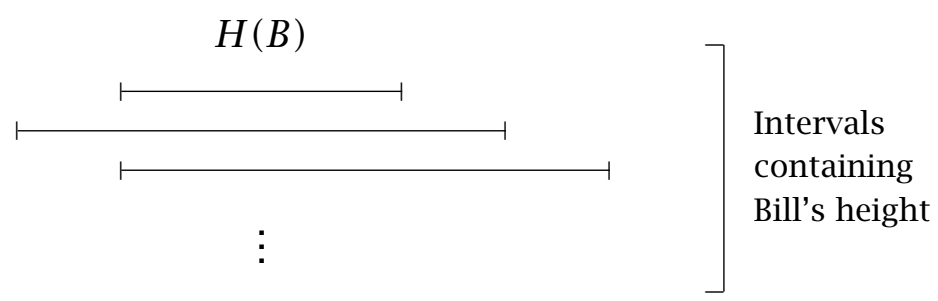

(80) $\quad \llbracket$ tall $\rrbracket=\lambda D . \lambda x . \operatorname{Height}(x) \in D$

I suggest that general mechanisms available in such situations enable us - in fact, force us - to pick from the set of intervals something that is suitable as the input to the comparative operator repeated in (81). I represent this selection mechanism as THE in $\left(79^{\prime \prime}\right)$ for the moment. This subsection asks what the appropriate meaning for THE is. (Note that the term 'selection' is not intended to imply that there is a genuine choice; I intend to provide one semantics for THE.)

$$
\llbracket-e r \rrbracket=\lambda d_{d} \cdot \lambda d_{d}^{\prime} \cdot d^{\prime}>d
$$

$\left(79^{\prime \prime}\right) \quad$ John is taller than THE $(\llbracket$ than-clause $\rrbracket)$

In the present case, THE could be an operator selecting the shortest interval from the set, i.e. Bill's height, cf. (82). This seems a natural choice, given that all other intervals contain extraneous material and that the point that really 'counts' is just Bill's height.

$$
\min \left(p_{\langle\langle d, t\rangle, t\rangle}\right)=\iota D \cdot p(D) \&\left[\neg \exists D^{\prime} . D^{\prime} \subset D \& p\left(D^{\prime}\right)\right]
$$

(shortest $p$ interval) 
Irene Heim and Danny Fox (p.c.) point out to me that the sense in which choosing the minimal interval is 'natural' is informativity. (83) below states what the maximally informative propositions out of a set of true propositions (say, a question meaning) are.

$$
\begin{aligned}
\text { a. } \quad \mathrm{m}_{-} \inf (w)\left(Q_{\langle s,\langle\langle s, t\rangle, t\rangle\rangle}\right)=\lambda q . Q(w)(q) \& \\
\neg \exists q^{\prime}\left[Q(w)\left(q^{\prime}\right) \& q \neq q^{\prime} \&\left[Q(w)\left(q^{\prime}\right) \rightarrow Q(w)(q)\right]\right]
\end{aligned}
$$

b. the maximally informative answers to a question $Q(w)(Q(w)$ the set of true answers to $Q$ in $w$ ) is the set of propositions $q$ in $Q(w)$ such that there is no other proposition $q^{\prime}$ in $Q(w)$ such that $Q(w)\left(q^{\prime}\right)$ entails $Q(w)(q)$ (i.e. if $q^{\prime}$ is in $Q(w)$ then so is $q$ ).

Informativity allows us to capture the fact that an appropriate answer to (84a) is the true answer that entails all the other true answers, i.e. John's maximal speed (for example the proposition that he drove $50 \mathrm{mph}$ ), and in a parallel way the minimum amount of flour that suffices in $(84 \mathrm{~b})$ (see Heim 1994; Beck \& Rullmann 1999).

(84) a. How fast did John drive?

$\lambda w . \lambda p . \exists d\left[p(w) \& p=\lambda w^{\prime}\right.$. John drove $d$-fast in $\left.w^{\prime}\right]$

\{that John drove $50 \mathrm{mph}$, that John drove $49 \mathrm{mph}$, that John drove $48 \mathrm{mph}, \ldots$.

b. How much flour is sufficient?

$\lambda w \cdot \lambda p . \exists d\left[p(w) \& p=\lambda w^{\prime} . d\right.$-much flour is sufficient in $\left.w^{\prime}\right]$

that $500 \mathrm{~g}$ is sufficient, that $501 \mathrm{~g}$ is sufficient, that $502 \mathrm{~g}$ is sufficient, ...

The definition can be extended to (intensions of) arbitrary sets in the following way:

$$
\begin{aligned}
& \operatorname{m\_ inf}(w)\left(p_{\langle s,\langle\alpha, t\rangle\rangle}\right)=\lambda q \cdot p(w)(q) \& \\
& \neg \exists q^{\prime}\left[p(w)\left(q^{\prime}\right) \& q \neq q^{\prime} \rightarrow\left[p(w)\left(q^{\prime}\right) \& p(w)(q)\right]\right]
\end{aligned}
$$

The instance of this generalization that we will be interested in is (86).

a. $\quad \operatorname{m}_{-} \inf (w)\left(p_{\langle s,\langle\langle d, t\rangle, t\rangle\rangle}\right)=\lambda D \cdot p(w)(D) \&$

$$
\neg \exists D^{\prime}\left[p(w)\left(D^{\prime}\right) \& D \neq D^{\prime} \&\left[p(w)\left(D^{\prime}\right) \rightarrow p(w)(D)\right]\right]
$$

b. the maximally informative intervals out of a set of intervals $p(w)$ is the set of intervals $D$ such that there is no other interval $D^{\prime}$ in $p(w)$ such that $p(w)\left(D^{\prime}\right)$ entails $p(w)(D)$ (i.e. if $D$ is in $p(w)$ then so is $D^{\prime}$ ). 
Fox \& Hackl (2006) argue that we want to extend the definition from the question case to others in order to capture the similarity between $(84 a, b)$ above and (87a), (88a). (87a) refers to the maximum speed John reached and (88a) refers to the minimum amount that suffices, both maximally informative in the sense of (85). The instance in (86) extends the analogy from $(84 a, b)$ and $(87 a),(88 a)$ to $(87 b),(88 b)$.

(87) a. the speed that John drove

b. than John drove

a. the amount of flour that is sufficient

b. than is sufficient

Hence, THE in $\left(79^{\prime \prime}\right)$ is m_inf, which yields a singleton, combined with taking from a set its only member (here represented with max). We can understand these operators as semantic 'glue' (a term introduced by Partee 1984, see also von Stechow 1995): operations that have to enter into composition, in addition to what the syntax strictly speaking provides, in order to make the sentence parts combinable. Their presence is required by the need for interpretability.

$\left(79^{\prime \prime \prime}\right) \quad$ John is taller than $\max \left(\mathrm{m}_{-}\right.$inf $(\llbracket$ than-clause $\left.\rrbracket)\right)$

The simple example allows me to emphasize another aspect of what I call the selection analysis: there is no choice in 'selecting' a point from a set of intervals. Only one interpretation is possible for (79). The 'glue' we have here is entirely semantic (and not, say, subject to pragmatic variability). Although we will see in a moment that quantifiers in than-clauses require some more elaboration, this will be preserved. Selection means, basically, taking from the minimal interval(s) the maximal element.

\subsubsection{Apparent wide scope universals}

Let's return to the now familiar example (89). We take the than-clause to have the denotation in $\left(89^{\prime}\right)$.

(89) a. John is taller than every girl is.

b. For every girl $x$ : John's height exceeds $x$ 's height. 
Quantifiers in than-clauses

$\left(89^{\prime}\right) \quad \llbracket[$ than every girl is tall $] \rrbracket=\lambda D^{\prime} . \forall x\left[\operatorname{girl}(x) \rightarrow \operatorname{Height}(x) \in D^{\prime}\right]$

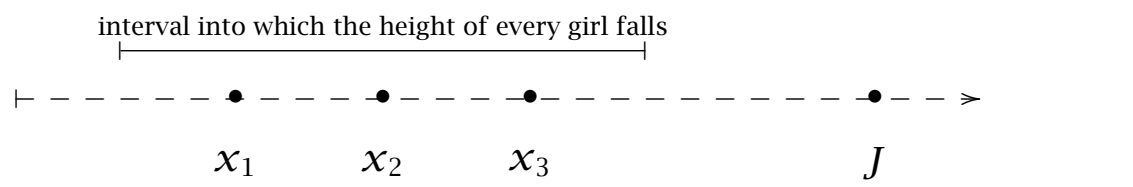

The intuitive truth conditions of (89) can be described as making a comparison between John's height and the end point of the interval into which all the girls' heights fall. If John is taller than the tallest girl, he is taller than all of them. Thus I propose that from the denotation of the than-clause that is given in $\left(89^{\prime}\right)$, we first choose the shortest = maximally informative interval that fits the description (i.e. that covers all the girls' heights) and then select the maximal point of that interval. ${ }^{4}$

(9o) John is taller than $\operatorname{Max}_{>}\left(\operatorname{m}_{-} \inf (\llbracket\right.$ than-clause $\left.\rrbracket)\right)$

$=$ John is taller than the height of the tallest girl

(91) and (92) below provide the relevant definitions. We extend the notion of the ordering relation underlying our degree scale from degrees to intervals, (91). We can then define the maximal element of a set of intervals, and finally the end point of an interval, (92).

(91) a. ordering of degree points: $d>d^{\prime}$

$d$ is larger than $d^{\prime}$

b. $\quad$ ordering of intervals: $I>J$ iff $\exists d\left[d \in I \& \forall d^{\prime}\left[d^{\prime} \in J \rightarrow d>d^{\prime}\right]\right]$

$I$ extends beyond $J$

(92) a. $\max _{>}:=$the max relative to the $>$relation on intervals or degrees

b. $\operatorname{Max}_{>}(p):=\max _{>}\left(\max _{>}(p)\right)$

$=$ the end 'point' of the interval that extends furthest

We straightforwardly derive the desired meaning. Other universal quantifiers can be treated in the exact same way. This is illustrated below with the

4 Fox \& Hackl propose to replace maximality with maximal informativity. I have not been able to develop an analysis that incorporates that proposal. The reason is lack of entailment among the degrees in the minimal than-clause interval: If I know of a degree $d$ that it falls in between the height of the smallest girl and the height of the tallest girl, I cannot infer that a degree $d^{\prime}$ larger than $d$ also falls within that interval ( $d^{\prime}$ might be beyond the height of the tallest girl) and I cannot infer that a smaller degree $d^{\prime \prime}$ also falls within that interval ( $d^{\prime \prime}$ might be below the height of the shortest girl). Therefore I will use both maximal informativity and ordinary maximality. 
familiar example containing predict. If my prediction was that John would be between $1.70 \mathrm{~m}$ and $1.80 \mathrm{~m}$ tall, then the interval $\left[1.7 \mathrm{O}^{-1.80}\right]$ is the unique shortest interval described by the than-clause. The end point of that interval is $1.80 \mathrm{~m}$, and the example is correctly predicted to be true if John is taller than $1.80 \mathrm{~m}$.

(93) a. John is taller than I had predicted (that he would be).

b. For every world compatible with my predictions:

John's actual height exceeds Johns height in that world.

(93') 【[than I had predicted (that he would be tall)]』= $\lambda D^{\prime} . \forall w\left[w R @ \rightarrow\right.$ John's height in $\left.w \in D^{\prime}\right]$

intervals into which John's height falls in all my predictions

$\left(93^{\prime \prime}\right) \quad J o h n$ is taller than $\operatorname{Max}_{>}\left(\mathbf{m}_{-} \inf (\llbracket\right.$ than-clause $\left.\rrbracket)\right)$

$=\mathrm{John}$ is taller than the height according to the tallest prediction

What I call selection yields the maximum relative to the ordering relation linguistically given - 'larger than' on the size scale in the case of taller. This follows from more general interpretive mechanisms suggested independently (compare Jacobson 1995; Fox \& Hackl 2006). Application of these mechanisms is required by the need for the than-clause to serve as input to the comparative operator.

\subsubsection{Apparent narrow scope existentials}

We can apply the same strategy to narrow scope existentials. This is illustrated with (94) below. In contrast to Heim's analysis and like Schwarzschild \& Wilkinson's, I assume that the than-clause denotes the set of intervals in (94') (once more via the shifted lexical entry for the adjective, (80)). Importantly, remember that I assume that the shift to intervals must take place locally, i.e. within the adjective phrase. I do not assume a genuine mobile operator Pi like Heim (2006b) does (whose LF for (94a) would give Pi wide scope relative to anyone). We dispense with the interpretations for than-clauses that were attributed to wide scope of the Pi operator.

(94) a. Mary is taller than anyone else is.

b. Mary's height exceeds the largest degree of tallness reached by one of the others.

$\left(94^{\prime}\right) \quad \llbracket[$ than anyone else is tall $] \rrbracket=\lambda D^{\prime} . \exists x\left[x \neq\right.$ Mary \& Height $\left.(x) \in D^{\prime}\right]$ intervals into which the height of someone other than Mary falls 
Quantifiers in than-clauses

The shortest = maximally informative than-clause intervals will be the heights of the other relevant people. (Thus we get rid of the intervals immediately.) Out of these, we choose the maximum. This results in the same meaning as under the classical analysis. Thus the same selection strategy that we used above will predict the right truth conditions. The analysis extends to other apparent narrow scope existentials like be allowed etc.

(95)

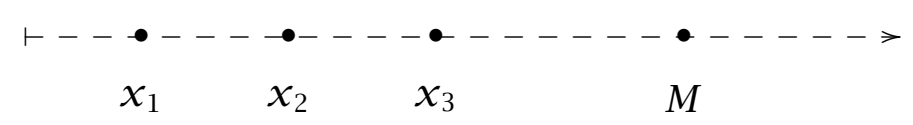

$\left(94^{\prime \prime}\right) \quad$ Mary is taller than $\operatorname{Max}_{>}\left(\mathrm{m}_{-} \inf (\llbracket\right.$ than-clause $\left.\rrbracket)\right)$

$=$ Mary is taller than the height of the tallest other person.

The selection strategy predicts the right truth conditions for these 'apparent narrow scope' and 'apparent wide scope' quantifier data without changing scope. This allows us to predict ungrammaticality of negation straightforwardly, as illustrated below.

\subsubsection{Negation}

Remember that the unacceptability of (96) could be understood in terms of an undefined contribution of the than-clause (von Stechow 1984; Rullmann 1995). The selection analysis presented here can retain this desirable prediction. The meaning of the than-clause is $\left(96^{\prime}\right)$, in accordance with what is said above. This is the only meaning possible for the than-clause.

(96) *John is taller than no girl is.

$\left(96^{\prime}\right) \quad \llbracket$ than no girl is tall $\rrbracket=\lambda D^{\prime}$. for no girl $x$ : Height $(x) \in D^{\prime}$ intervals into which the height of no girl falls

$\left(96^{\prime}\right)$ will not yield a well-defined meaning for the comparative. Just as in the original analysis of these data, the than-clause will not provide us with a maximum, since there is no largest interval containing no girl's height. Max> is undefined; hence negation in the than-clause leads to undefinedness of the comparative as a whole. Since there is no other option, we no longer face the problem of ruling out the apparent wide scope reading of the negative quantifier.

The simple data discussed in this subsection highlight the potential attraction of the selection analysis. We keep a simple semantics for the comparative 
Sigrid Beck

and don't double interpretive possibilities with a scoping mechanism. Next, we turn to all the complications.

\subsection{Refinement I: Have to-type modals}

This subsection concerns universal quantifiers that do not behave like every girl, predict and other apparent wide scope universals. Remember from Section 2 that modals like have to appear to favour a narrow scope interpretation rather than the apparent wide scope interpretation described and derived above for other universals.

(97) Mary wants to play basketball. The school rules require all players to be at least $1.70 \mathrm{~m}$.

$\left(97^{\prime}\right)$ a. Mary is taller than she has to be.

b. Mary's actual height exceeds the degree of tallness which she has in all worlds compatible with the school rules;

i.e. Mary's actual height exceeds the required minimum, $1.70 \mathrm{~m}$.

Keeping stable our assumptions about the meaning of than-clauses, we will assume (98) for this example. Selecting the maximum of the shortest than-clause interval will not yield the desired truth conditions this time, though: that would amount to the claim that Mary's height exceeds the maximum height permitted. The sentence intuitively says that Mary is above the required minimum. Contrasts like the one between have to and predict are of course what motivates the scope analysis (apparent wide scope for predict, apparent narrow scope for have to). A different description of the facts is that the example with predict (and similar examples with every girl, should, etc.) has a 'more than maximum' interpretation while have to can have a 'more than minimum' interpretation. I see the task for my approach as having to explain how factors independent of comparative semantics may result in a 'more than minimum' interpretation rather than the expected 'more than maximum' reading.

(98) 【than she has to be tall $\rrbracket=\lambda D^{\prime} . \forall w[w R @ \rightarrow$ Mary's height in $w \in$ $\left.D^{\prime}\right]$

intervals into which Mary's height falls in all worlds compatible with the rules

the beginning of this interval is below Mary's actual height, i.e. Mary's height exceeds the minimal element of the shortest than-clause interval 
Quantifiers in than-clauses

There are two analyses, as far as I am aware, that propose to reduce the variation in the interpretation of than-clauses with universal modals between maximum and minimum interpretation to independent factors, such that the readings collapse into one. Meier (2002) proposes that the ordering source that modal semantics uses is responsible for a contextually guided determination of the interpretation, explaining away apparent maxima and minima both. Krasikova (2008) examines the problem of have to-type modals in comparatives in particular and employs covert exhaustification to explain away apparent 'more than minimum' interpretations. While both approaches solve the problem at hand equally well for my purposes, I describe below Krasikova's suggestions because they seem to me to offer more promise for identifying which modal operators give rise to which reading(s).

Krasikova (2008) points out that whether we get a 'more than minimum' reading like the one illustrated above for this type of modal or a 'more than maximum' reading parallel to the reading illustrated for predict depends on the context an individual example is put into. Remember example (99) from above, which shows that have to-type modals may also give rise to a 'more than maximum' reading - the reading we expect under the present analysis. ${ }^{5}$ Thus what distinguishes have to-type modals from others is the availability of an apparent narrow scope reading (a 'more than minimum' reading under the present perspective).

(99) He was coming through later than he had to if he were going to retain the overall lead. (from Google, cited from Krasikova 2008)

Krasikova further observes that the universal modals that can give rise to the 'more than minimum'/apparent narrow scope reading are just the ones that occur in sufficiency modal constructions (SMC). An example of an SMC is given below (von Fintel \& Iatridou 2005).

(100) You only have to go to the North End (to get good cheese).

5 It is not at present clear to me under what circumstances a have to-type modal seems to permit a more-than-maximum interpretation. Relevant factors may be the choice of a negative polar adjective and a subjunctive-like interpretation (Danny Fox and Irene Heim, p.c.). Personally, I find this interpretation very hard to get. 
Sigrid Beck

$\left(100^{\prime}\right) \quad$ Truth conditions: You do not have to do anything more difficult than to go to the North End (to get good cheese).

Implicature: $\quad$ You have to go to the North End or do something at least as difficult (to get good cheese).

The combination of only and a modal in the SMC considers alternatives to the proposition that is the complement of have to, and ranks those alternatives on a scale. Plausible alternatives for our example and their ranking are given in (101). They provide the domain of quantification, C in (102); (102a) sketches a structure for the example, (102b) a meaning for 'only have to' and (102c) the outcome, which corresponds to the desired truth conditions (100'). Note that the SMC reading is one that identifies the point on a scale that is the minimum sufficiency point, as illustrated in (103).

(101) a. that you go to the nearest supermarket, that you go to the North End, that you go to New York, that you go to Italy

b. $\quad$ SUPER $<\mathrm{NE}<\mathrm{NY}<$ Italy (where ' $<$ ' means: is easier than)

(102) a. [[only have to $]_{C,<}[$ you go to the North End]]

b. $\llbracket[\text { only have to }]_{C,<} \rrbracket(p)(w)=1$ iff $\forall q[q \in g(C) \& \neg(q<p) \rightarrow \neg \llbracket$ have to $\rrbracket(q)(w)]$

c. For all $q$ such that $q$ is in $g(C)$ and $\neg(q<N E)$ : $\neg \llbracket$ have to $\rrbracket(q)$

(103)

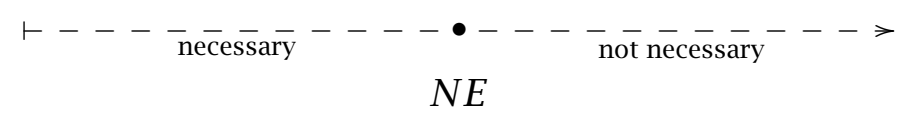

My sketch leaves unaddressed all the thorny problems of the SMC construction like the composition of only and have to with the rest of the clause, and the problem of only's presupposition; compare in particular von Fintel \& Iatridou 2005 and Krasikova \& Zhechev 2006. What is important for present purposes is Krasikova's observation that the interpretation that have to-type modals give rise to in than-clauses can be seen as an SMC interpretation. The 'more than minimum' interpretation just like the SMC identifies the point on a scale that is the minimum sufficiency point. Whatever is a plausible analysis of the SMC should be extendable to the problem at hand.

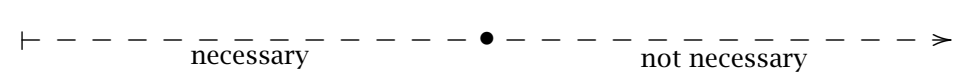

$1.70 \mathrm{~m}$ 
Krasikova suggests that have to-type modals can use Fox's (2007) covert exhaustivity operator EXH instead of only, whose meanings are basically the same. This is what happens in our comparatives, and this is responsible for the 'more than minimum' interpretition. ${ }^{6}$ A structure for the than-clause of $\left(97^{\prime} a\right)$ is given in (105a). Its interpretation using (102b) is (105b). Suppose now that the relevant alternatives are the propositions in (106a), which place Mary's height in varying intervals. Our context is such that difficulties arise with respect to reaching a certain height. Being short is not hard, being tall is difficult. Thus the ordering of the alternatives in (106a) is one that ranks them according to the height of the interval on the tallness scale into which Mary's height falls. The requirement easiest to meet is the minimal compliance height. Given this, (105b) can be paraphrased as (105c).

(105) a. $\llbracket\left(\right.$ than) $\left[1\left[[\mathrm{EXH} \text { has to }]_{C,<}\right.\right.$ Mary be $t_{1}$ tall $] \rrbracket$

b. $\quad\left[\lambda D^{\prime} . \forall q\left[q \in g(C) \& \neg\left(q<\lambda w\right.\right.\right.$. M's height in $\left.w \in D^{\prime}\right) \rightarrow$

$\neg \llbracket$ have to $\rrbracket(q)]]$

c. $\quad\left[\lambda D^{\prime}\right.$. nothing more difficult is required than for Mary's height to fall within $D^{\prime}$ ]

(106) a. $\left\{\lambda w\right.$. Mary's height in $w \in D_{1}, \lambda w$. Mary's height in $w \in D_{2}$, $\lambda w$. Mary's height in $\left.w \in D_{3}, \ldots\right\}$

b. If the ordering in terms of height is $D_{1}<D_{2}<D_{3} \ldots$ then: $\lambda w$. M's height in $w \in D_{1}<\lambda w$. M's height in $w \in D_{2}<$ $\lambda w$. M's height in $w \in D_{3}<\ldots$ (where '<' means: is easier; in our context, being shorter is easier than taller.)

Applying maximal informativity as usual yields the meaning below for the subordinate clause, the minimum 'point' as desired. Selection with Max is trivial; the resulting meaning is that Mary's actual height exceeds the minimum compliance height.

6 As an anonymous reviewer points out, this raises the question of why we cannot have an overt only in such sentences, cf. the ungrammaticality of (ia). The editors point out that extraction of the associate of only is not good, cf. (ib). This would have to be different for EXH than for only in order to answer the reviewer's question.

(i) a. *Mary is taller than she only has to be.

b. *WhoF did Mary only _ call? 
Sigrid Beck

(107) m_inf $([\lambda D$. nothing more difficult is required than for Mary's height to fall within D])

$=\{$ the minimum compliance height $\}$

$=\{[1.70-1.70]\}$

SMC readings of have to-type modals explain the 'more than minimum' reading that they can give rise to in comparative than-clauses with the single assumption that EXH takes the place of only. Internal to the subordinate clause, exhaustification occurs. Exhaustification of the than-clause reduces the than-clause interval to a point. The 'point' that exhaustification yields is the minimum compliance height.

I follow Krasikova in making the connection between SMC use and 'more than minimum' readings and in her analysis in terms of exhaustification. This allows me to maintain the selection analysis from the previous subsection. According to this analysis, have to-type modals don't require any revision of the semantics of comparative constructions. We need to take into account the special semantics of SMC modals instead. Contrary to appearances, we uniformly select a degree from an interval via $\mathrm{Max}_{>}$; with have to, we may apply $\mathrm{Max}_{>}$after exhaustification. This gives rise to a 'more than minimum'/apparent narrow scope reading. If exhaustification does not apply, we get the regular 'more than maximum' = apparent wide scope reading (cf. example (99) above). Modals that do not permit an SMC reading do not permit a 'more than minimum' reading either, because the 'more than minimum' reading is an SMC reading. I refer the reader to Krasikova 2008 for further discussion. Crucially for present purposes the correlation with SMC use provides an independent criterion for when to expect which reading. The contrast between the different kinds of universal quantifiers is not analysed as a scope effect. The analysis argued for here makes the interpetation of have to-type modals a property of those particular lexical items. They are the only apparent narrow scope items requiring special attention since in contrast to the scope analysis' procedure, apparent narrow scope existentials have already been taken care of.

\subsection{Refinement II: Indefinites, numeral NPs and the like}

This section concerns existential quantifiers that do not behave like NPI any and other apparent narrow scope existentials. The problem for the selection 
Quantifiers in than-clauses

strategy can be illustrated by the example below.

(108) John is taller than exactly five of his classmates are.

$\left(108^{\prime}\right) \quad$ a. Exactly five of John's classmates are shorter than he is.

b. \#John is taller than the tallest of his 5 or more classmates.

The intuitively available interpretation (108'a) looks once more like a straightforward wide scope reading of the numeral quantifier. Application of the selection strategy predicts an interpretation that is unavailable, $\left(108^{\prime} \mathrm{b}\right)$, as illustrated below.

(109) $\lambda D^{\prime}$. for exactly $5 x$ : $\max (\lambda d \cdot x$ is $d$-tall $) \in D^{\prime}$

intervals into which the height of exactly 5 classmates falls $\operatorname{Max}_{>}\left(\mathrm{m}_{-} \inf \left(\left[\lambda D^{\prime}\right.\right.\right.$. for exactly $5 x: \max (\lambda d$. $\mathrm{x}$ is $d$-tall $\left.\left.\left.) \in D^{\prime}\right]\right)\right)=$ the height of John's tallest classmate, as long as there are at least 5

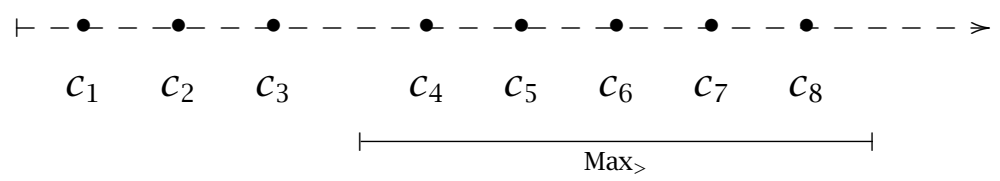

We face the combined challenge of (i) predicting the right interpretation and (ii) not predicting the non-existing one. I propose to tackle this problem through a more thorough analysis of numeral NPs. We will first consider indefinite NPs in the context of than-clauses and then move on to numerals and example (108).

\subsubsection{Singular and plural indefinites}

Singular indefinites allow in principle two interpretations in than-clauses: an apparent wide scope and an apparent narrow scope reading. Which reading(s) is/are possible depends on the indefinite as well as the sentence context. We have seen examples with NPIs in which only the narrow scope reading is available. An example that has a wide scope reading is given in (110). (111) and (112) provide two examples which I take to be genuinely ambiguous (the English version of (111) probably is too, although native speakers seem to have some difficulty judging the example).

(110) a. John is taller than one of the girls is.

b. There is a girl $x$ such that John is taller than $x$. 
Sigrid Beck

Annett hat lauter gesungen als eine Sopranistin.

Annett has louder sung than a soprano

'Annett sang more loudly than a soprano did.'

(German)

$\left(111^{\prime}\right) \quad$ a. There is a soprano $x$ such that Annett sang more loudly than $x$.

b. Annett sang more loudly than any soprano did.

(112) Sveta could solve this problem faster than some undergrad could.

$\left(112^{\prime}\right) \quad$ a. There is an undergrad $x$ such that Sveta could solve this problem faster than $x$ could.

b. Sveta could solve this problem faster than any undergrad could.

For examples with apparent narrow scope existentials it was demonstrated above (with an NPI indefinite, anyone else) how the selection analysis can derive an appropriate interpretation corresponding to the apparent narrow scope reading. What about the apparent wide scope reading? One option open to us is to acknowledge that indefinites quite often give rise to apparent wide scope readings - so-called specific readings - and to adopt whatever mechanism is appropriate for the analysis of specific readings in general for apparent wide scope indefinites in than-clauses. This is what I will do, and I use the choice function mechanism as the probably best known analysis of specific indefinites (e.g. Reinhart 1992; Kratzer 1998; but see Endriss 2009 for a different analysis). I illustrate with example (113a) from Heim 1982, where $a$ friend of mine can have apparent scope over the conditional.

(113) a. If a cat likes a friend of mine, I always give it to him.

There is a friend of mine such that if a cat likes him, I give it to him.

b. $\exists f: C H(f) \&$ [if a cat likes $\mathrm{f}$ (friend of mine), I give it to him] If a cat likes the friend of mine selected by $f$ ( $f$ a choice function), I give it to him.

Furthermore, I will assume that indefinite NPs, e.g. with German ein ('a'), are ambiguous between the 'normal' interpretation ' $\exists x$ ' (existential quantification over individuals) and the 'specific' interpretation ' $\exists f$ ' (existential quantification over choice functions). Below I provide a selection analysis of the two readings of (111) under those assumptions. ${ }^{7}$ On this analysis, the apparent narrow scope reading amounts to a ' $\exists x$ ' interpretation and

7 I use the German example because the larger English inventory of indefinites makes it hard for me to determine which examples are genuinely ambiguous. 
Quantifiers in than-clauses

the apparent wide scope reading amounts to a ' $\exists f$ ' interpretation for the indefinite.

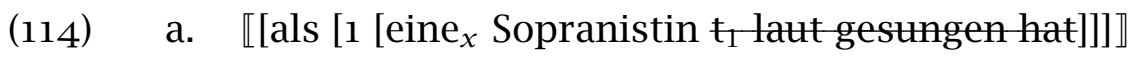
$=\left[\lambda D^{\prime} . \exists x\left[\operatorname{soprano}(x) \& \max (\lambda d . x\right.\right.$ sang $d$-loudly $\left.\left.) \in D^{\prime}\right]\right]$ intervals that cover the loudness of soprano singers

Annett sang more loudly than $\operatorname{Max}_{>}\left(\mathrm{m}_{-} \inf \left(\left[\lambda D^{\prime} . \exists x[\operatorname{soprano}(x) \& \max (\lambda d . x\right.\right.\right.$ sang $d$-loudly $) \in$ $\left.\left.\left.\left.D^{\prime}\right]\right]\right)\right)$

$=$ Annett sang more loudly than the loudest soprano.

$=$ Annett sang more loudly than any soprano did.

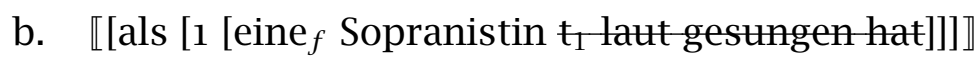
$=\left[\lambda D^{\prime} . \max \left(\lambda d \cdot f\right.\right.$ (soprano) sang $d$-loudly) $\left.\in D^{\prime}\right]$ intervals that include the loudness of the soprano selected by $f$

$\exists f: C H(f)$ \& Annett sang more loudly than $\operatorname{Max}_{>}\left(\mathrm{m}_{-} \inf \left(\left[\lambda D^{\prime} . \max \left(\lambda d . f\right.\right.\right.\right.$ (soprano) sang $d$-loudly) $\left.\left.\left.\in D^{\prime}\right]\right)\right)$ $=$ Annett sang more loudly than the soprano selected by $f(f$ a choice function).

$=$ There is a soprano $x$ such that Annett sang more loudly than $x$.

I further assume that the usual factors (in particular, the nature of the indefinite and what readings the sentence context permits) decide when we can get which reading(s) of a singular indefinite. I have nothing illuminating to say about the particulars of this; note, however, that I do assume that apparent narrow scope readings are possible with indefinites/existentials other than NPIs. My intuitions regarding German indefinites like jemand (someone) + anders/sonst (other/else), wh-word + other/else convince me of this in particular, because these indefinites are not, I believe, plausibly analysed as polarity items, nor are they plausibly analysed as generic (hence not existential). Other languages' inventory of indefinites may make my view of what the interpretive possibilities of existentials in than-clauses are appear less obvious. I am grateful in particular to Sveta Krasikova for discussion of this point. 
Sigrid Beck

(115) a. Hier ist es schöner als anderswo.

here is it nicer than elsewhere

'It's nicer here than it is elsewhere.'

b. possible reading:

It is nicer here than it is anywhere else.

(116) a. Sam ist schneller als jemand anderes/sonstwer.

Sam is faster than someone other/someone else

'Sam is faster than another person.'

b. possible reading:

Sam is faster than anyone else is.

Also, the data in (117) (in addition to (111) above) provide an indefinite, ein anderer ('another'), that is ambiguous. Both (117a) and (117b) were collected informally from the web. Context makes it clear that (117a) is intended to mean 'faster than everyone else' and (117b) is intended to mean that someone was slower.

(117) a. Wir denken 7-mal schneller, als ein anderer reden kann. we think 7 times faster than an other talk can 'We think seven times faster than anyone else can talk.'

b. Die meisten überholten mich, aber $a b$ und zu war ich auch the most passed me but now and then was I also mal schneller als ein anderer. once faster than an other 'Most people passed me, but now and then I was faster than someone.'

Matters look somewhat different when we consider plural indefinites. Beginning with bare plurals, note that many examples sound strange (thank you to Irene Heim for example (118)).

(118) a. John is taller than a giraffe.

b. ??John is taller than giraffes.

a. Prof. Shimoyama hat einen längeren Beitrag geschrieben Prof. Shimoyama has a longer contribution written als eine Doktorandin. than a Ph.D. student 'Prof. Shimoyama wrote a longer contribution than a Ph.D. student.'

(ok: $\exists x$, ok: $\exists f$ ) 
Quantifiers in than-clauses

b.??Prof. Shimoyama hat einen längeren Beitrag geschrieben

Prof. Shimoyama has a longer contribution written

als Doktorandinnen.

than Ph.D. students

'Prof. Shimoyama wrote a longer contribution than Ph.D. students.'

(120) a. Hans ist schneller gelaufen als eine Schwester von Greg.

Hans ran faster than a sister of Greg's. (ok: $\exists x$, ok: $\exists f$ )

b. ??Hans ist schneller gelaufen als Schwestern von Greg.

Hans ran faster than sisters of Greg's.

c. Hans ist schneller gelaufen als einige Schwestern von Greg.

Hans ran faster than several sisters of Greg's. (ok: $\exists f)$

The version with the singular indefinite can have an apparent narrow scope or an apparent wide scope interpretation (with some speaker variation regarding which interpretation is favoured). It is known that bare plurals prefer narrow scope interpretations - let's say this implies that the choice function ' $\exists f$ ' interpretation is dispreferred. What the oddness of the plural data tells us, then, is that there is something unexpectedly wrong with the non-specific ' $\exists X$ ' interpretation of the plural indefinite (I write capital ' $X$ ' to indicate plurality, in contrast to ' $x$ ' for singular). Note that the data (118)-(120) improve when some or several/einige is added to the plural indefinite. They then have an apparent wide scope or ' $\exists f$ ' interpretation. The following generalization emerges:

(121) $\operatorname{Max}_{>}\left(m_{-} \_\inf (\lambda D . \exists X[\ldots])\right)$ is dispreferred relative to

$$
\operatorname{Max}_{>}\left(\mathrm{m}_{-} \inf (\lambda D . \exists x[\ldots])\right) .
$$

A plural indefinite ambiguous between ' $\exists X$ ' and ' $\exists f$ ' will yield ' $\exists f$ '.

A plural indefinite that prefers the ' $\exists X$ ' interpretation will sound strange.

Why should a plural indefinite sound odd unless it can easily reveice a specific interpretation? The generalization is intuitively unsurprising once we examine the ' $\exists X$ ' interpretation more closely. Careful consideration as to what it would mean in the case of (120), provided in (122a), reveals that (given that there is more than one sister of Greg's) it would be true iff the sentence with the singular ' $\exists x$ ' ('any sister of Greg's) would be true. I suggest that this makes the interpretation (122a) somehow inappropriate for the example. Perhaps this can be seen as a matter of economy: the plural has no purpose, 
Sigrid Beck

hence cannot be used gratuitously.

a. \#Hans ran faster than

$\operatorname{Max}_{>}\left(\mathrm{m}_{-} \inf \left(\left[\lambda D^{\prime} . \exists X\left[* \operatorname{sister}(X) \& \forall x \in X: x\right.\right.\right.\right.$ 's speed $\left.\left.\left.\in D^{\prime}\right]\right)\right)$ $=$ Hans ran faster than any sister of Greg's.

b. $\exists f: C H(f) \&$ Hans ran faster than

$\operatorname{Max}_{>}\left(\mathrm{m}_{-} \inf \left(\left[\lambda D^{\prime} . \forall x \in f(*\right.\right.\right.$ sister $): \max (\lambda d . x$ ran $d$-fast $) \in$ $\left.\left.D^{\prime}\right]\right)$ )

= Hans ran faster than each of the sisters selected by $f$ ( $f$ a choice function).

(dispreferred with bare plural, ok with some/several)

(123) is a first shot at what the relevant constraint might effect. The reading that survives, (122b), is one in which, compared to the corresponding singular indefinite, the plural serves a purpose.

(123) Ban on Unmotivated Pluralization (BUMP):

Do not quantify over a plurality if quantification over a singularity lets you infer the same reference.

It would be good to be able to reduce this phenomenon to other cases with a similar semantics. ${ }^{8}$ Below I relate than-clauses to definite descriptions and embedded questions (I am once more inspired by Danny Fox (p.c.) in making this connection). The idea is that all three constructions share some sense of maximality and/or maximal informativity (Fox \& Hackl 2006 and the above considerations). So (124a) refers to the maximal, and in the sense of (85) above, the maximally informative speed that John ran; (124b) will require the maximally informative answer, i.e. the maximal speed John reached; and according to the analysis developed here, (124c) is of course analogous.

(124) a. the speed that John ran

b. how fast John ran

c. than John ran

8 An anonymous reviewer and Danny Fox pointed out to me that a plural is not generally dispreferred when a singular yields the same interpretation, contrary to a claim I made in an earlier version of this paper. Negation and other downward monotone environments allow plural indefinites, as the example in (i) illustrates. I thank them for pointing out this flaw to me.

(i) We don't sell apples (??an apple) in this store.

There were no women present. 
The following three sets of data replace the proper name in (124) with various kinds of indefinites in the three constructions. The plain singular indefinite is fine and picks out the fastest speed in the definite description and the question as well as in the than-clause - in addition to a possible specific reading. The bare plurals are somewhat odd, which we can explain if a constraint like the BUMP above is operative (and the ' $\exists f$ ' interpretation is dispreferred). The last set with plural some indefinites are fine and have the specific reading. Plural indefinites with some are different from bare plurals in easily allowing an ' $\exists f$ ' interpretation.

(125) a. the speed that a sister of Greg's ran

b. how fast a sister of Greg's ran

c. than a sister of Greg's ran

(126) a. ??the speed that sisters of Greg's ran

b. ??how fast sisters of Greg's ran

c. ??than sisters of Greg's ran

(127) a. the speed that some sisters of Greg's ran

b. how fast some sisters of Greg's ran

c. than some sisters of Greg's ran

These data share the problem of having to determine unique reference from a set via maximality/informativity. They motivate the way that the BUMP is phrased above. Perhaps it is the nature of maximality/informativity as 'glue' that makes it sensitive to such a constraint: the step of postulating such operators is an inference one draws to have things make sense, and such inferences are subject to 'making sense'-type of requirements like the BUMP. But I hasten to add that I am by no means confident that I understand what is at stake and that more work ought to be done in figuring out what the BUMP is really about.

I conclude this subsection with a couple of comments on further kinds of indefinites. The first data point confirms the perspective on the data developed so far with the German example (128), where the obligatorily weak lauter (several/many) sounds very strange. Only einige (several) is acceptable, under an apparent wide scope reading.

(128) Annett hat lauter gesungen als einige/??lauter Sopranistinnen. Annett has louder sung than several sopranos 'Annett sang more loudly than several sopranos.' 
This can be understood if lauter disprefers a choice function analysis, permitting only the BUMP violating reading $\left(128^{\prime} \mathrm{a}\right)$, while einige yields an acceptable interpretation in terms of $\left(128^{\prime} \mathrm{b}\right)$. Our assumption about lauter vs. einige is confirmed by (129), where only the version with einige allows the specific interpretation of the NP 'relatives of mine'.

$\left(128^{\prime}\right) \quad$ a. \#Annett sang more loudly than $\operatorname{Max}_{>}\left(\mathrm{m}_{-} \inf \left(\left[\lambda D^{\prime} . \exists X[* \operatorname{soprano}(X) \&\right.\right.\right.$

$$
\left.\left.\left.\forall x \in X: \max (\lambda d \text {. } x \text { sang } d \text {-loudly }) \in D^{\prime}\right]\right)\right)
$$

$=$ Annett sang more loudly than any soprano.

b. $\exists f: C H(f)$ \& Annett sang more loudly than $\operatorname{Max}_{>}\left(\right.$m_inf $_{-}\left(\left[\lambda D^{\prime} . \forall x \in f(*\right.\right.$ soprano $): \max (\lambda d . x$ sang $d$-loudly $) \in$ $\left.\left.\left.D^{\prime}\right]\right)\right)$

= Annett sang more loudly than each of the sopranos selected by $f$ ( $f$ a choice function)

(129) a. Wenn einige Verwandte von mir sterben, erbe ich einen Bauernhof.

b. Wenn lauter Verwandte von mir sterben, erbe ich einen Bauernhof.

'If several relatives of mine die, I will inherit a farm.'

Similarly, we might expect that NPIs in than-clauses will only be licensed on the apparent narrow scope reading ' $\exists x$ ' (perhaps they have no ' $\exists f$ ' interpretation, or perhaps that interpretation would fail to satisfy the licensing requirements on their context). This predicts that singular NPIs only have an apparent narrow scope reading. It also makes the interesting prediction that plural NPIs should be odd in than-clauses. (130b) is judged degraded compared to (130a) and (130c) by some speakers, but not by all.

(130) a. John solved this problem faster than any girl did.

b. ??John solved this problem faster than any girls did.

c. John solved this problem faster than any of the girls did.

I don't understand why some people judge (130b) to be fine; I wonder whether a Free Choice interpretation of any girls is possible for those who accept the sentence.

A final remark: it is not the case that plural indefinites in than-clauses are generally bad, not even narrow scope ones. The data in (131) embed the indefinite beneath another operator, and the BUMP does not apply. 
Quantifiers in than-clauses

(131) a. More people bought books than read magazines.

b. I buy books more often than I buy magazines.

To sum up: indefinites are semantically ambiguous, and this shows up in than-clauses just like it does elsewhere. Apparent wide scope of indefinites is analysed as pseudoscope: a specific reading. Sometimes one interpretation is excluded by independent factors. In particular an economy constraint BUMP can rule out ' $\exists X$ ' for plural indefinites in than-clauses. ${ }^{9}$ The analysis rests on how the semantic glue interacts with intervals, and on how the interpretation is derived. I assume that the semantic glue is sensitive to BUMPy constraints, i.e. that it is a natural place for their application.

\subsubsection{Numerals}

With these results regarding indefinites in place, let us next be somewhat more precise in our semantic analysis of 'exactly $n$ '. Like Gajewski (2008), we employ a more elaborate analysis of these numerals (compare Hackl 2001a,b;

9 It is not clear to me that competing analyses of quantifiers in than-clauses can easily explain the pattern of singular vs. plural indefinites. To give an example, the Pi analysis (supposing it goes along with my assumptions about the semantics of plural indefinites) predicts for (ia) a narrow scope reading (ic) in addition to the wide scope reading (ib).

(i) a. John was faster than (some) sisters of Greg's were.

b. $\exists X[* \operatorname{sister}(X) \& \forall x \in X: \operatorname{Speed}(\operatorname{John})>\operatorname{Speed}(x)]$

'Some sisters of Greg's were slower than John.'

c. $\quad \operatorname{Speed}(\mathrm{John})]>\max (\lambda d . \exists X[* \operatorname{sister}(X) \& \forall x \in X: \operatorname{Speed}(x) \geq d])$

'John's speed exceeds the speed reached by the slowest member of a plurality of sisters of Greg's'

$=$ John was faster than the second fastest sister of Greg's.

d. $\exists d[\operatorname{Speed}(\mathrm{John}) \geq d \& \operatorname{NOT} \exists X[* \operatorname{sister}(X) \& \forall x \in X: \operatorname{Speed}(x) \geq d]]$

e. Suppose Greg has three sisters:

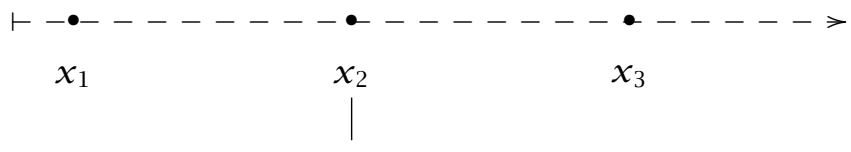

largest speed reached by

every member of a plurality

of sisters of Greg's

An interpretation corresponding to (ic) is not available and would have to be excluded - in the plural case, but not in the singular. The reading predicted by the NOT-theory, (id), is parallel. Depending on how hard it is to do so, an argument might be gained for the selection analysis from the pattern of singular vs. plural indefinites in than-clauses. 
Krifka 1999 on the semantics of such NPs). Remember the simple example (66) and its analysis.

(66) a. Exactly three girls weigh $50 \mathrm{lb}$.

b. [EXACT [XP (exactly) three $\mathrm{F}_{\mathrm{F}}$ girls weigh $\left.\left.50 \mathrm{lb}.\right]\right]$

$\left(66^{\prime}\right) \llbracket$ three $\mathrm{F}_{\mathrm{F}}$ girls weigh $50 \mathrm{lb} . \rrbracket_{o}=\exists X[* \operatorname{girl}(X) \& \operatorname{card}(X)=3 \& *$ weigh. $50 . \mathrm{lb}(X)]$ $\llbracket$ three $\mathrm{F}_{\mathrm{F}}$ girls weigh $50 \mathrm{lb} . \rrbracket_{f}=$ $\{\exists X[* \operatorname{girl}(X) \& \operatorname{card}(X)=n \& *$ weigh. 50. $\mathrm{lb}(X)]: n \in N\}$

(67) $\llbracket \mathrm{EXACT} \rrbracket\left(\llbracket \mathrm{XP} \rrbracket_{f}\right)\left(\llbracket \mathrm{XP} \rrbracket_{o}\right)=1$ iff $\llbracket \mathrm{XP} \rrbracket_{o}=1 \& \forall q \in \llbracket \mathrm{XP} \rrbracket_{f}: \neg\left(\llbracket \mathrm{XP} \rrbracket_{o} \rightarrow q\right) \rightarrow \neg q$ 'Out of all the alternatives of $\mathrm{XP}$, the most informative true one is the ordinary semantics of XP.'

(68) $\llbracket(66 b) \rrbracket=1$ iff $\exists X[* \operatorname{girl}(X) \& \operatorname{card}(X)=3 \& *$ weigh. 50. $\mathrm{lb}(X)] \&$ $\forall n[n>3 \rightarrow \neg \exists X[* \operatorname{girl}(X) \& \operatorname{card}(X)=n \& *$ weigh. 50. lb $(X)]]$ iff $\max (\lambda n . \exists X[* \operatorname{girl}(X) \& \operatorname{card}(X)=n \& *$ weigh. $50 . \operatorname{lb}(X)])=3$

This step does not immediately solve our problem. If we give the than-clause in (108) the semantics in (132), nothing changes: we still compare with the tallest of John's classmates, as long as there are at least five. Notice, however, that this interpretation is just as strange as the plain plural indefinite ' $\exists X$ ' interpretation above, since the number information serves no real purpose for the truth conditions.

(108) John is taller than exactly five classmates of his are.

(132) $\lambda D^{\prime} . \max \left(\lambda n . \exists X\left[* \operatorname{classmate}(X) \& \operatorname{card}(X)=n \& * \operatorname{Height}(X) \in D^{\prime}\right]\right)=$ 5

Intervals into which the height of exactly five of John's classmantes falls

(133) John is taller than

$\operatorname{Max}_{>}\left(\mathrm{m}_{-} \inf \left(\lambda D^{\prime} . \max (\lambda n . \exists X[* \operatorname{classmate}(X) \& \operatorname{card}(X)=n \&\right.\right.$

$$
\left.\left.\left.* \text { Height }(X) \in D^{\prime}\right]\right)=5\right) \text { ) }
$$

(133') Presupposition: John has at least five classmates. Assertion: He is taller than any of them.

This reading is thus ruled out by the same constraint BUMP. We should then alternatively consider a choice function analysis of the indefinite ' $n$ class- 
Quantifiers in than-clauses

mates'. I combine this below with the assumption that exactly is evaluated in the matrix clause. In (134), we derive the desired interpretation.

(134) $\max (\lambda n . \exists f[C H(f) \&$ John is taller than

$\operatorname{Max}_{>}\left(\operatorname{m}_{-} \inf \left(\lambda D^{\prime} . \forall x \in f((\lambda X . * \operatorname{classmate}(X) \& \operatorname{card}(X)=n)\right.\right.$ :

$\left.\left.\operatorname{Height}(x) \in D^{\prime}\right]\right)=5$

'the largest number $n$ such that John is taller than the tallest of the $n$ classmates of his selected by some choice function $f$ is 5 .'

An LF of example (108) representing a version of Krifka's analysis looks as in (135).

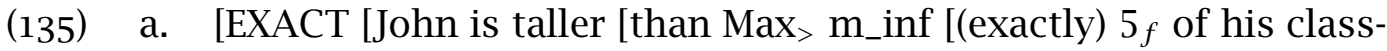
mates are tall]]]]

b. Out of all the alternatives of the form 'John is taller than $n$ of his classmates are', the most informative true one is 'John is taller than 5 of his classmates are'.

The applicability of the constraint BUMP to numeral indefinites is empirically supported by the data below, which behave in a parallel way to plural indefinites with some, for example.

(136) a. the speed that two finalist drove

b. how fast two finalist drove

c. than two finalist drove

Thus I suggest that a proper semantic analysis of numeral NPs makes the facts compatible with a selection solution after all.

\subsubsection{Further relevant cases}

The analysis developed here for indefinite NPs in than-clauses needs to be extended to NPs with many and most, which show the same apparent wide scope interpretations we observed for numerals.

(137) a. John is taller than many of his classmates are.

b. There are many classmates of John's such that he is taller than they are.

(138) a. John is taller than most of his classmates are.

b. For most $x, x$ a classmate of John's: John is taller than $x$. 
I will make further use of the semantics developed by Hackl (2001a,b, 2009) for these NPs, according to which 'many $N$ ' is an indefinite NP including a gradable adjective in the positive form, and 'most $N$ ' is correspondingly a superlative. This makes feasible analyses that can be paraphrased in the following way: ${ }^{10}$

$\left(137^{\prime}\right) \quad$ John is taller than the tallest of the many-membered group of classmates of his selected by $f$ ( $f$ a choice function).

$\left(138^{\prime}\right) \quad$ John is taller than the tallest of the group selected by $f$, which comprises a majority of his classmates ( $f$ a choice function).

More detailed analysis are given below ((139) provides the two potential readings of (137) and (140)-(142) analyse (138)). Besides being able to predict the existing readings, the BUMP constraint in (123) will rule out the ones that are intuitively unavailable.

a. \#John is taller than

$\operatorname{Max}_{>}\left(\mathrm{m}_{-} \inf \left(\left[\lambda D^{\prime} . \exists X[* \operatorname{classm}(X) \& \operatorname{many}(X) \& \forall x \in X:\right.\right.\right.$ $\left.\left.\left.\operatorname{Height}(x) \in D^{\prime}\right]\right)\right)$

$=$ John is taller than any classmate (as long as there are many).

b. $\exists f: C H(f) \&$ John is taller than

$\operatorname{Max}_{>}\left(\operatorname{m}_{-} i n f\left(\left[\lambda D^{\prime} . \forall x \in f(\lambda X . * \operatorname{classm}(X) \& \operatorname{many}(X))\right.\right.\right.$ :

$=$ John is taller than each of the many classmates selected by $f$ ( $f$ a choice function)

(140) 【than $\left[1\left[\emptyset_{X}\right.\right.$ most of his classmates are $t_{1}$ tall $\left.]\right] \rrbracket=$ $\left[\lambda D^{\prime} . \exists X \exists d[* \operatorname{classm}(X) \& d-\operatorname{many}(X) \& \forall Y \in C[Y \neq X \& * \operatorname{classm}(Y) \rightarrow\right.$ $\neg d$-many $\left.(Y)] \& \forall x \in X: \operatorname{Height}(x) \in D^{\prime}\right]$

intervals that contain the heights of a majority of John's classmates

(141) 【than $\left[1\left[\emptyset_{f}\right.\right.$ most of his classmates are $t_{1}$ tall $\left.]\right] \rrbracket=$ $\left[\lambda D^{\prime} . \forall x \in f(\lambda X . \exists d[* \operatorname{classm}(X) \& d\right.$-many $(X) \& \forall Y \in C[Y \neq$

10 An anonymous reviewer points out that this predicts that these NPs can have the same specific readings we know from indefinites. I concur, but would like to point out that this prediction arises from an analysis of these quantifiers as indefinites, not from the application of that analysis to than-clauses. The empirical test cases include data like (i) below.

(i) a. If many relatives of mine die, I will inherit a farm.

b. If most relatives of mine die, I will inherit a farm. 
Quantifiers in than-clauses

$X \& * \operatorname{classm}(Y) \rightarrow \neg d$-many $\left.(Y)]): \operatorname{Height}(x) \in D^{\prime}\right]$

intervals that contain the heights of the majority of John's classmates selected by $f$

$(142)$

a. \#John is taller than

$\operatorname{Max}_{>}\left(\operatorname{m}_{-} \inf \left(\left[\lambda D^{\prime} . \exists X \exists d[* \operatorname{classm}(X) \& d\right.\right.\right.$-many $(X) \& \forall Y \in C[Y \neq$ $X \& * \operatorname{classm}(Y) \rightarrow \neg d$-many $\left.\left.\left.(Y)] \& \forall x \in X: \operatorname{Height}(x) \in D^{\prime}\right]\right)\right)$

$=$ John is taller than the tallest of any majority of his classmates.

$=$ John is taller than any of his classmates.

b. $\exists f: C H(f)$ \& John is taller than

$\operatorname{Max}_{>}\left(\operatorname{m}_{-} \inf \left(\left[\lambda D^{\prime} . \forall x \in f(\lambda X . \exists d[* \operatorname{classm}(X) \& d-\operatorname{many}(X) \&\right.\right.\right.$ $\forall Y \in C[Y \neq X \& * \operatorname{classm}(Y) \rightarrow \neg d$-many $(Y)]): \operatorname{Height}(x) \in$ $\left.D^{\prime}\right]$

= John is taller than the tallest of the majority of John's classmates selected by $f$ ( $f$ a choice function)

$=$ For most $x, x$ a classmate of John's: John is taller than $x$.

To sum up: this subsection has analysed the available vs. unavailable readings of indefinite NPs in than-clauses using a choice function mechanism plus a constraint on unmotivated pluralization. The formulation of the BUMP in (123) is offered as a first version of the constraint we need; what we want to derive is that it is strange to say 'John is taller than exactly three girls are' if we meant, and might as well have said 'John is taller than any girl is'. Since this seems eminently reasonable, I am hopeful that a good way of stating the relevant constraint exists. Given this, the present section has extended the selection analysis to apparent wide scope indefinite NPs of various kinds (including numerals, many and most), using a pseudoscope mechanism argued for extensively for indefinites independently of comparatives. The comparative semantics itself remains simple.

\subsection{Refinement III: Differentials}

The final kind of data that does not immediately fall out from the selection analysis is represented by example (143) below: a than-clause containing a universal quantifier in combination with a differential.

(143) a. John is exactly $2^{\prime \prime}$ taller than every girl is.

b. For every girl $x$ : John is exactly $2^{\prime \prime}$ taller than $x$. 
Compared to Heim, and also Schwarzschild \& Wilkinson, we seem to have a problem. Heim's analysis can derive the intuitive interpretation as shown below.

(144) [[than every girl is tall] [5 [John is exactly $2^{\prime \prime}$ taller $\left.\left.\left.t_{5}\right]\right]\right]$

$\left(144^{\prime}\right)$ 【[than [1 [every girl [2 [[Pi $\left.\mathrm{t}_{1}\right]\left[3\left[\mathrm{t}_{2}\right.\right.$ is $\mathrm{t}_{3}$ tall] $\left.\left.\left.\left.\left.]\right]\right]\right]\right]\right] \rrbracket=$

$$
\lambda D^{\prime} . \forall x\left[\operatorname{girl}(x) \rightarrow \operatorname{Height}(x) \in D^{\prime}\right]
$$

intervals into which the height of every girl falls

(145) $\llbracket(144) \rrbracket=\left[\lambda D^{\prime} . \forall x\left[\operatorname{girl}(x) \rightarrow \operatorname{Height}(x) \in D^{\prime}\right]\left(\lambda d\right.\right.$. John is exactly $2^{\prime \prime}$ taller than $\left.d\right)$ $=$ for every girl $x$ : John is exactly $2^{\prime \prime}$ taller than $x$

Choice of $\mathrm{Max}_{>}$on the other hand predicts a different interpretation, which does not seem right for (143):

(146) John is exactly $2^{\prime \prime}$ taller than $\operatorname{Max}_{>}\left(\mathrm{m}_{-} \inf (\llbracket\right.$ than-clause $\left.\rrbracket)\right)$ $=$ John is exactly $2^{\prime \prime}$ taller than the tallest girl.

The intuitively available reading of (143a) can be described as one in which we assume that all the girls reach the same height. I call this an assumption of equality among the individuals universally quantified over, EQ for short. The EQ appears to speak in favor of a scope solution since it is entailed by the truth conditions resulting from giving the universal wide scope over the comparison. It is not entailed by the truth conditions according to the selection analysis, although it is of course compatible with the truth conditions in (146) that the girls all have the same height.

Sentence (143a) exemplifies a problem that arises when a than-clause containing a universal quantifier is combined with a differential that includes exactly, at most or almost. A differential including at least does not distinguish between the two sets of truth conditions.

(147) a. John is at most/almost $2^{\prime \prime}$ taller than every girl is.

b. For every girl $x$ : John is no more than $2^{\prime \prime}$ taller than $x$

c. \#John is no more than $2^{\prime \prime}$ taller than the tallest girl.

(148) a. John is at least $2^{\prime \prime}$ taller than every girl is.

b. For every girl $x$ : John is at least $2^{\prime \prime}$ taller than $x$

c. John is at least $2^{\prime \prime}$ taller than the tallest girl.

An unmodified differential does not constitute evidence as strong as an exactly/at most-type differential, because, while it gives rise to the usual 
strengthening implicature that amounts to an exactly reading, this implicature can be canceled. If we suppose the implicature to be present, the unmodified differential is parallel to exactly.

(149) a. John is $2^{\prime \prime}$ taller than every girl is.

b. Implicature: John is no more than $2^{\prime \prime}$ taller than every girl is.

c. John is $2^{\prime \prime}$ taller than every girl is, perhaps more.

To sum up the picture so far, differentials with exactly and at most, and perhaps simple differentials, seem to be problematic for the selection analysis as opposed to the scope analysis.

However, there is more to say about this issue empirically and theoretically. Beginning with the theoretical side, note that the interpretation of the matrix clause in (144) was simplified in terms of not giving the differential quantifier exactly $2^{\prime \prime}$ independent scope. ${ }^{11}$ Data like (150) show that such expressions do take scope, however:

(150) You are allowed to be exactly $6^{\prime}$ tall.

(151) $\llbracket$ exactly $6^{\prime} \rrbracket=\lambda D \cdot \max (D)=6^{\prime}$

$\left(150^{\prime}\right) \quad$ a. $\quad \max (\lambda d . \exists w[w A c c @ \&$ you are $d$-tall in $w])=6^{\prime}$

The largest permitted height for you is $6^{\prime}$.

b. $\exists w\left[w A c c @ \& \max (\lambda d\right.$. you are $d$-tall in $\left.w)=6^{\prime}\right]$

It is permitted that you be exactly $6^{\prime}$ tall.

Hence, in addition to (a more elaborate version of) (144) above, the LF and interpretation in (152) become possible. For the Pi theory, this leads to availability of the analysis in (153).

(152) [[exactly $\left.2^{\prime \prime}\right]$ [4 [[than every girl is tall] [5 [John is $t_{4}$ taller $\left.\left.\left.\left.\left.t_{5}\right]\right]\right]\right]\right]$

$\left(144^{\prime}\right) \llbracket\left[\right.$ than [1 [every girl [2 [[Pi $\left.\mathrm{t}_{1}\right]\left[3\left[\mathrm{t}_{2}\right.\right.$ is $\left.\left.\left.\left.\left.\left.\left._{3} \operatorname{tall}\right]\right]\right]\right]\right]\right]\right]=\lambda D^{\prime} . \forall x[\operatorname{girl}(x) \rightarrow$ $\left.\operatorname{Height}(x) \in D^{\prime}\right]$

intervals into which the height of every girl falls

$(153) \quad \llbracket(152) \rrbracket=\left[\right.$ exactly $\left.2^{\prime \prime}\right]\left(\lambda d^{\prime} .\left[\lambda D^{\prime} . \forall x\left[\operatorname{girl}(x) \rightarrow \operatorname{Height}(x) \in D^{\prime}\right]\right.\right.$

( $\lambda d$. John is $d^{\prime}$ taller than $d$ )

$=$ [exactly $\left.2^{\prime \prime}\right]\left(\lambda d^{\prime}\right.$. for every girl $x$ : John is $d^{\prime}$ taller than $\left.x\right)$

$=\max \left(\lambda d^{\prime}\right.$. for every girl $x$ : John is $d^{\prime}$ taller than $\left.x\right)=2^{\prime \prime}$

'The largest amount that John is taller than every girl is $2^{\prime \prime} . '$

11 Thanks to Danny Fox for drawing my attention to this point. 
Note that this LF no longer predicts all the girls to have the same height. It says that John is exactly $2^{\prime \prime}$ taller than the tallest girl - just like the selection analysis. It is thus not clear that the predictions of the scope analysis are really different from, and superior to, the selection analysis.

Next, let's take a closer look at the data. Above, we identified as a problem that EQ is not predicted, the assumption that all individuals universally quantified over have the same height (or whatever the gradable predicate measures). However, the data are quite difficult. While I agree with the perception in the literature that in (143a) the EQ is plausible, it is clear that it does not always arise. Below are some examples where it doesn't; (154)-(156) are collected from the internet. ${ }^{12}$ The reader can convince her/himself that further relevant data can easily be found. The difficulty in determining the interpretation of data with nominal universal quantifiers is related to the point mentioned in Section 2 about differentials and intensional verbs. I mention in $\left(156^{\prime}\right)$ a suggestive example also collected from the web.

(154) Aden had the camera for \$10o less than everyone else in town was charging.

(155) WOW! Almost 4 seconds faster than everyone else, and a 9 second gap on Lance.

(156) Jones was almost an inch taller than the both of them. (the both of them $=$ John Lennon and Paul McCartney, Jones $=$ Tom Jones. The author thinks that Jones was $5^{\prime} 11^{\prime \prime}$ and that Paul McCartney was about $5^{\prime} 10^{\prime \prime}$. John Lennon is reported to be shorter than McCartney by about an inch.)

$\left(156^{\prime}\right) \quad$ I finished 30 seconds faster than I expected. [... ] I know my 300 yard time more accurately now.

(the continuation suggests that the speaker's expectation was a range rather than a precise point in time.)

The examples are straightforwardly analysed using Max $>$ to determine the relevant 'point' provided by the than-clause. ${ }^{13}$ The differential measures the

12 A naive Google search has not unearthed a clearly relevant example with an exactlydifferential.

13 A different type of example illustrated below is difficult for both a scope and a selection analysis. I find it hard to decide what such examples mean precisely. It seems plausible to me that we select some kind of 'point' from the meaning of the than-clause, but not in the way described in the text. 
Quantifiers in than-clauses

distance between that and the main clause degree. This is demonstrated for (155) below.

$\left(155^{\prime}\right) \quad$ a. \#For all $x, x \neq Z:$ : $Z$ was) almost 4 seconds faster than $x$ (wide scope)

b. ( $Z$ was) almost 4 seconds faster than $\operatorname{Max}_{>}\left(\operatorname{m}_{-} \inf \left(\lambda D^{\prime}\right.\right.$. for all $x \neq$ $\left.Z: \operatorname{Speed}(x) \in D^{\prime}\right)$ )

$=Z$ was almost 4 seconds faster than the next fastest person. (selection $\operatorname{Max}_{>}$)

We face the task of figuring out what distinguishes (143) from (154)-(156), i.e. why EQ arises in some data but not all. I would like to ask this question in terms of how the selection analysis might predict not only (154)-(156), but also (143). To this effect, let's take a closer look at the combination of a differential with a comparative.

Note that we understand a claim like (157a) relative to a plausible level of granularity. For us to judge (157a) to be true, it is in most contexts sufficient to be precise up to the level of a few millimeters. Suppose on the other hand that $(157 \mathrm{~b})$ is about a sensitive piece of machinery. A one millimeter margin could very well not be acceptable. This means that what we call John's height, or that rod's length, is actually somewhat fuzzy: it is a 'blob' or an interval on the relevant scale whose size depends on context. The sensitivity to a level of precision is not represented in the standard truth conditions of the two examples given in $\left(157^{\prime}\right)$.

(157) a. Mary is exactly $2 \mathrm{~cm}$ taller than John is.

b. This rod is exactly $2 \mathrm{~cm}$ longer than that rod is.

$\left(157^{\prime}\right) \quad$ a. Height $($ Mary $)=\operatorname{Height}($ John $)+2 \mathrm{~cm}$

b. Length(this rod $)=$ Length $($ that $\operatorname{rod})+2 \mathrm{~cm}$

To capture this, I follow Krifka (2007) in assuming that a scale can be divided into different units. A unit on the scale then has to be identified that can count as a 'point' at the contextually relevant level of granularity. Which

(i) a. Ben was almost a year older than everyone else in his class (because he had just missed the deadline for the previous school year).

b. \#For all $x \neq$ Ben: Ben was almost a year older than $x$.

c. \#Ben was almost a year older than the next oldest in his class.

d. ?The others' ages center around a point almost a year younger than Ben. 
division we assume depends on context. Talking about a length of $1.80 \mathrm{~m}$ for example could then refer to a very short or a somewhat larger stretch of the scale, depending on the relevant standard of precision/unit size. I talk about unit size as granularity.

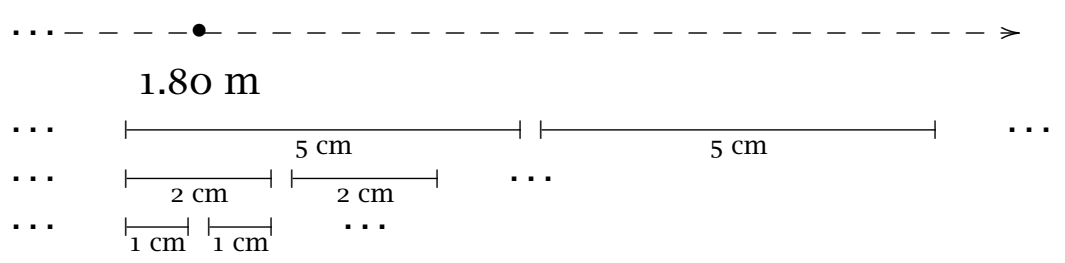

I make use of Schwarzschild's (1996) notion of a cover as a division of an entity into its contextually relevant parts, and apply it to scales in (159). Covers provide the relevant granularity.

(159) Let $\langle S,>\rangle$ be a scale. Then Cov is a cover of $S$ if Cov is a set of subsets of $S$ such that each $d$ in $S$ is in some set in Cov, each set in Cov is contiguous and no two sets in Cov overlap. Assume Cov to be the set of intervals that are of the contextually relevant size.

I furthermore revise the definition of an end "point" from (16o) to (161) ((161b) is the informal version, (161c) the more precise version employing covers). Note that the distinction between points and intervals dissolves under this view because what we usually call a point is an interval on the scale whose size depends on context.

a. $\operatorname{Max}_{>}\left(p_{\langle\langle d, t\rangle, t\rangle}\right):=\max _{>}\left(\max _{>}(p)\right)$ $=$ the end point of the interval that extends furthest

b. Let $S$ be a set ordered by $R$. Then $\max _{R}(S)=\iota s\left[s \in S \& \forall s^{\prime} \in\right.$ $\left.S\left[s R s^{\prime}\right]\right]$

(161) a. $\operatorname{Max}_{>}\left(p_{\langle\langle d, t\rangle, t\rangle}\right):=\operatorname{end}_{>}\left(\max _{>}(p)\right)$ $=$ the end 'blob' of the interval that extends furthest

b. $\quad \operatorname{end}_{>}(D):=\iota d . d \subseteq D \& \neg \exists d^{\prime}\left[d^{\prime} \subseteq D \& d^{\prime}>d\right] \& d$ counts as a point at the relevant level of granularity

c. Let Cov be the set of intervals that are of the contextually relevant size.

$\operatorname{end}_{>, \operatorname{Cov}}(D):=\iota d . d \subseteq D \& d \in \operatorname{Cov} \&$

$$
\neg \exists d^{\prime}\left[d^{\prime} \subseteq D \& d \neq d^{\prime} \& d^{\prime} \in \operatorname{Cov} \& d^{\prime}>d\right]
$$


Quantifiers in than-clauses

Supposing that we talk about what we roughly call $1.80 \mathrm{~m}$, the meanings of our two than-clauses could (depending on context, i.e. the relevant cover) come out as in (162). It is thus in the nature of scales that they have a part/whole structure whose units are determined in a context dependent manner.
a. $\operatorname{Max}_{>, \operatorname{Cov}_{1}}($ than John is tall $)=[1.798-1.803]$
(a $0.5 \mathrm{~cm}$ unit)
b. $\operatorname{Max}_{>, \mathrm{Cov}_{2}}$ (than that rod is long $)=[1.7998-1.8002] \quad(\mathrm{a} 0.4 \mathrm{~mm}$ unit)

Let's consider differentials under this refined understanding of scales. A differential measures the distance from the "point" referred to in the matrix to the "point" referred to in the than-clause, "point" being determined by the relevant unit size. Note that a plausible granularity for the than-clause has to match the granularity level suggested by the differential. If the two do not match, an odd sentence results. I call this a granularity clash. In the example below, we know that it is impossible to determine to the second the amount of time that it took John to learn French. The than-clause comes inherently with a coarse granularity, which clashes with the granularity of the differential in (163b).

(163) a. Mary learned arithmetic faster than John learned French.

b. ?Mary learned arithmetic faster than John learned French by 7 minutes 23 seconds.

c. Mary learned arithmetic faster than John learned French by several months.

We can generalize from the example as follows. In a comparative of the form (164a), it must at least be given that the cover of the relevant interval that the than-clause provides (via informativity) furnishes units that are smaller than the differential; i.e. (164b) is a requirement for the comparative to make sense. If that is the case, then the unit picked out as a "point" by Max> will also be smaller than the differential (164c). The comparative can then measure the gap between the main clause degree and the maximum of the than-clause with the differential ((164d)). If the maximum itself is larger, this will be impossible. In our example, suppose that we can with exceptional precision determine to the day how long it took Mary to learn arithmetic and John to learn French. We cannot reasonably measure the gap between two days in terms of the differential ' 7 minutes 23 seconds'. The level of 
Sigrid Beck

granularity relevant for the than-clause has to make sense in relation to the differential.

(164) a. Main Clause Differential than $D$

b. for all $U \in \operatorname{Cov}: U<\operatorname{Diff}$

c. $\quad$ Since $\operatorname{Max}_{>, \text {Cov }}(D) \in \operatorname{Cov}: \operatorname{Max}_{>, \operatorname{Cov}}(D)<\operatorname{Diff}$

d. $\operatorname{Max}_{>, \operatorname{Cov}}($ Main Clause $)=\operatorname{Diff}+\operatorname{Max}_{>, \text {Cov }}(D)$

The reasoning works out given that the cover, and therefore the unit that counts as 'maximal point', is determined locally, i.e. than-clause internally, independently of the differential which will then either fit or clash. ${ }^{14}$

I think that granularity offers an explanation for the interpretive effect I call EQ. Consider the situation depicted below for (165). If we have no further information regarding the situation, the girls' sizes can be far apart. This would indicate a large interval. The idea is that the semantics of the thanclause itself indicates possible Covers. There is then a danger that we have a coarse-grained cover. A reasonable division of into relatively long units, hence $\mathrm{Max}_{>}$is long. This would be incompatible with the differential - a granularity clash. That is, a sentence in which the than-clause indicates a real spread (e.g. because of a universal quantifier) brings with it the danger of a granularity mismatch with a differential.

(165) John is exactly $2^{\prime \prime}$ taller than every girl is.

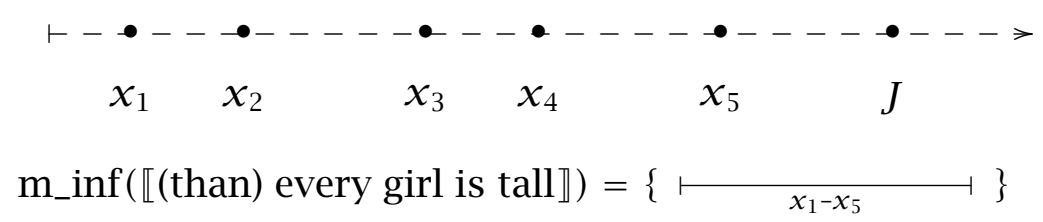

14 A similar effect can be observed with Covers in the plural domain in examples like (i) below.

(i) a. The women and the men love their child.

b. The Smiths and the Johnsons love their child.

Suppose we are talking about Angelina and Reginald Johnson and Mary and John Smith. Then the two subjects in (ia) and (ib) refer to the same group, but make different covers salient (Schwarzschild 1996). By virtue of the cover suggested by the subject, (ia) tends to be understood as 'the women love their child and the men love their child', which is unexpected. (ia) amounts to 'the Smiths love their child and the Johnsons love their child', which is more expected. The point is that the subject group autonomously makes salient a cover, whether this leads to a plausible interpretation of the whole or not. 
Quantifiers in than-clauses

The Cover indicated by the than-clause may agree with the differential only under an additional assumption of closeness of the individual "points" covered by the than-clause interval. My suggestion is that if a potential granularity clash could only be avoided under an additional assumption of closeness, one tends to assume equality and a default Cover of the thanclause interval $D$ in terms of the singleton set $\{D\}$. This is the EQ. In short, without an informative context, there is a danger of a granularity clash. The danger is avoided by the EQ. The EQ would under this analysis be an extra assumptions speakers make in order to ensure that a sentence is meaningful. (Note that the EQ is not the weakest assumption one could make to ensure that; perhaps it is the simplest assumption.)

The data above for which the selection analysis automatically makes good predictions with $\mathrm{Max}_{>}$, (154)-(156), are such that we have a rather clear expectation about the kind of interval denoted by the than-clause - the range within which the individual degrees fall is fixed. The context is rich, and no problems with granularity arise. Thus a genuine Max interpretation (i.e. one in which we pick out the maximum from a genuine spread) is possible without further assumptions. This distinguishes those data from our original example (165). I suggest that danger of a granularity clash leads to EQ: to supposing that the 'points' that are in danger of being spread over too large an interval in fact collapse into one. We expect that it should depend on the amount of information available on the interval covered by the thanclause whether we get an EQ interpretation or a genuine Max interpretation. Additional information to the effect that the points are not the same, but close enough together for the purposes of the differential, may make the EQ unnecessary and thus make a genuine $\mathrm{Max}_{>}$interpretation possible for our EQ data. This appears to me to be correct:

(167) Background: we are running an experiment in which we vary the growth conditions of seedlings. In particular, we test different fertilizing agents (ViagraFlor, Dung ${ }^{\mathrm{TM}}$, ComposFix and GuanoPlus) and their effect on how fast our seedlings grow. After two weeks, it is reported that:

(168) The ComposFix seedlings are exactly $2^{\prime \prime}$ taller than all the others. (Max> possible)

Danger of granularity clash arises in uninformative contexts and triggers EQ. I should be able to take the same than-clauses that occured in Max $\mathrm{x}_{>}$examples 
Sigrid Beck

and place them into a less fortunate context, and trigger EQ. Again, this seems the right prediction.

(169) a. This pot dries out exactly 40 min faster than all the others.

b. This T-Shirt dries exactly 20 min faster than all the others.

(EQ likely)

We see that minimal pairs can be found that have essentially the same comparative (differential plus comparative adjective plus than-clause) but differ as to informativity of background context regarding the than-clause interval. An uninformative context makes us assume that the interval is point-like, so that $\mathrm{Max}_{>}$will be well defined and suitable-EQ. If we have enough background information to be sure that the Max $>$ unit in the thanclause interval is suitable, we do not panic, make no extra assumptions, and can get a genuine $\mathrm{Max}_{>}$interpretation as expected.

Things are different with an existential quantifier. Consider (170) against the same background as before. The minimal than-clause intervals will be the heights of the individual girls. Max $>$ will be well defined and suitable without any additional assumptions, and will make this a comparison between John's height and the height of the tallest girl, as desired.

(170) John is exactly $2 \mathrm{~cm}$ taller than any girl is. $\operatorname{Max}_{>}\left(m_{-}\right.$inf $(\llbracket($ than $)$ any girl is tall $\left.\rrbracket)\right)$

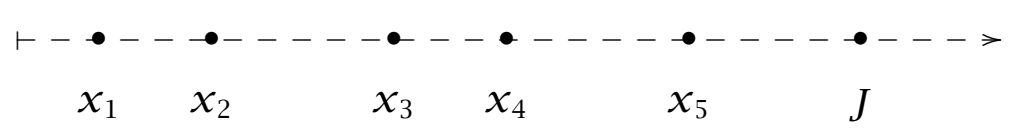

I conclude that the selection strategy provides a reasonable perspective on differential comparatives. It depends on context whether we get an EQ interpretation or a genuine $\mathrm{Max}_{>}$interpretation, and the selection strategy can explain this. I will not investiate here what a scope strategy could say about the data.

A more general remark: At this point in the analysis, a pragmatic element has entered the picture. The 'glue' I have been talking about so far is genuinely semantic and seems fully determined (as far as I can see) given the requirement of interpretability. But scales (following the insights represented by Krifka's work) require reference to context and include a pragmatic element in the shape of the cover. In addition to the maximality/informativity 
operators themselves, we need the contextually relevant part/whole structure of the scale to interpret a particular example. Properties of the cover become relevant in particular in the presence of differentials, and speakers may be lead to make extra assumptions (EQ). The fuzzy nature of the data, in my opinion, speaks in favour of the idea that some kind of pragmatic glue is required to make things work out. Depending on the context, speakers may or may not have an easy time figuring out what the necessary glue is. That said, a remaining caveat is a more thorough empirical understanding of the data with differentials.

\section{Summary and conclusions}

\subsection{Summary}

Building on work primarily by Schwarzschild \& Wilkinson and Heim, I propose an analysis of quantifiers in than-clauses in which the quantifier is interpreted inside the than-clause. A shift from degrees to intervals of degrees makes this possible. Despite appearances, there is no scope interaction between quantifier and shifter or quantifier and comparison operator. Instead, there is uniformly selection of a point from the subordinate clause interval. The analysis takes from Schwarzschild \& Wilkinson the step to intervals. It shares with Heim that comparison is ultimately reduced to comparison of points. Intervals are not directly compared. In contrast to Heim and the subsequent NOT-theory, apparent scope effects like the interpretation of have to-type modals and exactly $n$ NPs have been explained away via recourse to alternative interpretational mechanisms, which have been argued for independently of than-clauses (in these two examples: exhaustification and an alternative semantics for exactly-numerals). My strategy is motivated by the lack of clear scope interaction in than-clauses.

One feature of the proposal is that the semantics of the comparative operator is very simple. It is the same semantics that one needs for data like (172a), namely one in which the first argument of the comparative operator is a degree, (172C). Maximality is still used in clausal comparatives like the ones we have discussed, but it is independent of the comparative operator.

(172) a. John is taller than $1.70 \mathrm{~m}$.

b. [[-er [than $1.70 \mathrm{~m}]]$ [2 [John is $\mathrm{t}_{2}$ tall]]]

c. $\llbracket$-er $\rrbracket=\lambda d_{1} \cdot \lambda d_{2} \cdot d_{2}>d_{1}$ 
It is in this sense the analysis developed here is in my opinion 'simpler' than Schwarzschild \& Wilkinson's. The complexity that is no doubt there in the present analysis consists in the assumption that general interpretive strategies like informativity and maximality are involved (plus in independent complications like the availability of specific readings for indefinites and the like). Also, the semantics is no longer completely determined by compositional semantics. Data with differentials could only be analysed by enriching the classical semantics with pragmatic notions (covers, contextual background). However, this aspect of the proposal is supported by contextual variability of the judgements and thus has to be part of a successful analysis.

In order to ultimately evaluate the success of my proposals, the whole approach needs to also be extended to adverbials. I will not attempt to do so now. Other considerations concern a more detailed analysis of the various modals (including might) and an investigation of the interaction of several scope bearing elements inside a than-clause. I give some representative data below and acknowledge the need for further work on the subject (compare Schwarzschild \& Wilkinson 2002, Heim 2006b, Schwarzschild 2008). Finally, I admit that I have no analysis for Sauerland's (2008) example (174), for which he provides a solution in terms of Heim's theory.

(173) a. It is hotter here today than it often is in New Brunswick.

b. It is hotter today than it might be tomorrow.

c. Sveta solved this problem faster than someone else could have.

(174) Ekaterina is an odd number of centimeters taller than each of her teammates.

These issues are left for future work.

\subsection{Where do the intervals come from?}

There is one important theoretical question left for the intervals-plus-selection analysis to answer: where do the intervals come from? In Section 3 I made the assumption that basic adjective meanings already contained intervals:

(175) $\llbracket$ tall $\rrbracket=[\lambda D . \lambda x . \operatorname{Height}(x) \in D]$

I could alternatively have assumed that the operator Pi from Heim 2006b shifts the standard adjective meaning to (175). 
Quantifiers in than-clauses

(176) Pi shifts from degrees to intervals: [1 [AP [Pi $\left.\mathrm{t}_{1}\right]\left[3\left[{ }_{\mathrm{AP}} \mathrm{t}_{2}\right.\right.$ is $_{3}$ tall]]]]

(177) $\quad$ a. $\llbracket$ tall $\rrbracket=[\lambda d . \lambda x$. Height $(x) \leq d]$

b. $\llbracket \mathrm{Pi} \rrbracket=[\lambda D \cdot \lambda P . \max (P) \in D]$

c. $\quad[\lambda D . \llbracket \operatorname{Pi} \rrbracket(D)(\llbracket \operatorname{tall} \rrbracket(x))]=[\lambda D . \operatorname{Height}(x) \in D]$

Since Pi on the analysis pursued here always takes scope immediately next to the adjective, this would have served no particular purpose and I simplified to (175). But a problem for assuming (175) as the basic meaning of a gradable adjective is that it is very weak. This creates problems for example for the negation theory of antonymy (compare e.g. Heim 2006a). (178a) analyses the negative polar adjective short as the negation of tall. I fail to be able to imagine how a parallel strategy for the interval based meaning (178b) could be successful.

(178) a. $\llbracket$ short $\rrbracket=[\lambda d . \lambda x . \neg \operatorname{Height}(x) \geq d]=[\lambda d . \lambda x$. Height $(x)<d]$

b. $\llbracket$ short $\rrbracket=\lambda D$. $\lambda x$. Height $(x) \notin D$

So if the intervals do not come into the semantics via a motivated independent (since mobile) operator Pi, and nor are they plausibly basic, how do they come in? It would be attractive to say that intervals enter the semantics because, that is, if and only if, they are needed. That is what I would like to think, and (175) really was a simplification for the sake of uniformity that I think of as preliminary.

An idea for how to bring intervals into the semantics when needed that is due to Heim (2009) is given below. We begin by observing that a relation can be expressed between a plurality and a part of a scale - a degree 'blob'.

(179) a. (You have to be $5^{\prime}$ tall to enter.)

Our children are that tall.

b. (Bill's GPA is 3.75.)

Sam's grades are that good, too.

We see a parallel to expressing a relation between a plurality and a mass noun. The example (180a) can be represented as in (180b) with the meaning in (180c) in mind for the relation between the two objects of drink - a cumulative interpretation (see e.g. Beck \& Sauerland 2000 and all the earlier work cited there that they rely on).

(180) a. Our children drank the milk.

b. $* * \operatorname{drank}(M)(C)$ 
c. $\forall x \leq C: \exists y \leq M: \operatorname{drank}(y)(x) \& \forall y \leq M: \exists x \leq C: \operatorname{drank}(y)(x)$

All children participated in drinking the milk, and all parts of the milk were drunk by one of the children.

Transferring the analysis to our degree example yields (181).

(181) a. Our children are that tall.

b. $* * \operatorname{tall}(D)(C)$

c. $\forall x \leq C: \exists d \leq D: \operatorname{tall}(d)(x) \& \forall d \leq D: \exists x \leq C: \operatorname{tall}(d)(x)$

All the children's heights fall into $D$, and all parts of $D$ contain the height of a child.

It is easy to apply the same analysis to a than-clause containing a definite plural, and it yields the set of intervals that we need according to the analysis in Section 3. Comparison will be with the maximum point in that set and the sentence is predicted to mean that our children are shorter than John.

a. (John is taller) than our children are.

b. $\lambda D . * * \operatorname{tall}(D)(C)$

c. $\lambda D . \forall x \leq C: \exists d \leq D: \operatorname{tall}(d)(x) \& \forall d \leq D: \exists x \leq C$ : $\operatorname{tall}(d)(x)$ intervals that contain the heights of all our children (and nothing else)

Note that the notion of degree 'blobs' that have a part/whole structure is anticipated by the reference to covers in Section 3. A cover provides us with the relevant parts of the degree scale. We are consistently assuming a mass like structure of the degree scale. To make the connection clear, $\left(182^{\prime}\right)$ provides a more complete formalisation of (180a) which includes covers (compare Beck 2001 for this kind of use for covers).

a. $\quad \lambda D .[* * \lambda d . \lambda x . d \in \operatorname{Cov} \& x \in \operatorname{Cov} \& \operatorname{tall}(d)(x)](D)(C)$

b. $\lambda D . \forall x[x \leq C \& x \in \operatorname{Cov} \rightarrow \exists d[d \leq D \& d \in \operatorname{Cov} \& \operatorname{tall}(d)(x)]] \&$

$\forall d[d \leq D \& d \in \operatorname{Cov} \rightarrow \exists x[x \leq C \& x \in \operatorname{Cov} \& \operatorname{tall}(d)(x)]]$ (suppose that the relevant parts of 'the children' are the individual children, and that the relevant parts of the cover are the units according to granularity)

Example (182)/(182') derives a set of intervals, as pluralities of degrees, as the meaning of a than-clause via plural predication. What would we need 
to do in order for this idea to apply to the range of data examined in this paper? I briefly discuss three issues for which this change in perspective is reelvant: (i) universal quantifiers, (ii) singular quantifiers, and (iii) maximal informativity.

First, regarding universal quantifiers: The introduction of intervals analogously to (182) would have to happen with universal quantifiers of various kinds, in particular universal nominals and intensional verbs (cf. our two representative examples every girl and predict). Regarding intensional verbs, there is a proposal by Bošković \& Gajewski (2008) that instead of universal quantification over worlds (183a) they (or at least some of them) involve sum formation (183b).

(183) a. $\llbracket$ believe $_{x} \rrbracket=\lambda p . \forall w\left[w \in B E L_{x} \rightarrow p(w)\right]$

b. $\llbracket$ believe $_{x} \rrbracket=\max \left(\lambda W . W \in * B E L_{x}\right)$

This makes possible the following analysis of a than-clause with an intensional verb (in the simpler version without covers):

(184) a. (John is taller) than you believe.

b. $\lambda D .[* * \lambda w . \lambda d$. John is $d$-tall in $w]\left(\max \left(\lambda W . W \in * B E L_{\text {you }}\right)\right)(D)$

c. $\quad \lambda D . \forall w \leq \max \left(\lambda W . W \in * B E L_{\text {you }}\right): \exists d \leq D: \operatorname{tall}(w)(d)($ John $) \&$ $\forall d \leq D: \exists w \leq \max \left(\lambda W . W \in * B E L_{\text {you }}\right): \operatorname{tall}(w)(d)(\mathrm{John})$

intervals that contain John's height in all your belief worlds (and nothing else)

Nominal universal quantifiers, it has been observed, can sometimes be used to introduce a plurality, although this is not always easily possible. Perhaps (185) involves a reinterpretation as a plural definite NP. The same reinterpretation would be responsible for the interpretation of the than-clause in (186) in case the girls are of varying heights. This might make sense of my abovementioned intuition that a definite plural is more acceptable than a universal NP.

(185) a. Everyone gathered in the hallway.

b. ?Every student gathered in the hallway.

(186) a. John is taller than every girl is.

b. 'every girl' $\rightarrow G$ (the plurality of girls)

c. $\lambda D . * * \operatorname{tall}(D)(G)$ 
d. $\lambda D \cdot[\forall x \leq G: \exists d \leq D: \operatorname{tall}(d)(x)]$

$$
\&[\forall d \leq D: \exists x \leq G: \operatorname{tall}(d)(x)]
$$

intervals that contain the heights of all the girls (and nothing else)

Thus it can be argued that a plural analysis of intervals can capture these data $^{15}$ The discussion from Section 3 is (almost - see below) unchanged; what changes is what happens below the level of AP, so to speak (the predication ' $\mathrm{x}$ is $d$-tall'): what we assumed to be basic in (175) is now compositionally derived via pluralization mechanisms. Next, let's reconsider data with singular quantificational elements:

(187) a. Mary is taller than anyone else is.

b. *John is taller than no girl is.

$\left(187^{\prime}\right)$ a. John is taller than some girls are.

b. $\lambda D . \exists X:[\forall x \leq X: \exists d \leq D: \operatorname{tall}(d)(x)]$

$$
\&[\forall d \leq D: \exists x \leq X: \operatorname{tall}(d)(x)]
$$

c. $\quad \lambda D \cdot[\forall x \leq f(*$ girl $): \exists d \leq D: \operatorname{tall}(d)(x)]$

$$
\&[\forall d \leq D: \exists x \leq f(* \operatorname{girl}) . \operatorname{tall}(d)(x)]
$$

There would be no reason to introduce intervals in the data with singular indefinites and negative quantifiers. Remember from Section 3.1 that in these cases, we got rid of the intervals immediately anyway (maximal informativity reduced the contribution of the than-clause to the set of individual heights). Now, we could just revert to the classical analysis for those data. This is not an unwelcome result, since the classical analysis offers a successful solution for them. Pluralization as the trigger for the introduction of intervals will continue to play a role for plural indefinites (see example $\left(187^{\prime}\right)$ ); the discussion in Section 3.3 is thus also in important respects unchanged.

Finally, we need to think once more about the role of maximal informativity. Plural semantics keeps intervals small. The truth conditions of cumulation are such that the pluralised relation holds between the plurality and the smallest interval that covers all the individuals in the plurality (cf. the second conjunct in (181c) and the following analyses). This may make

15 I am not sure at this point what to say about the have to-type modals. Perhaps (as non-negraising verbs) they do not have a plural analysis. We then revert to the classical analysis. If they do have a plural semantics, the story in Section 3.1 is maintained. The first version relates the behavior of a modal to neg-raising, the second to SMC use. 
Quantifiers in than-clauses

m_inf unnecessary, leaving us with iterated maximality. Again this can be seen as a welcome result.

The attraction of this approach is, as said above, that intervals enter the picture only when there is a real need for them. The idea is entirely compatible with the selection analysis and in my view very desirable. Why did I not set out in this fashion in Section 3? I am not quite confident enough of the story in (185), (186), and too many details remain to be worked out, plus the data need to be examined more carefully. As things stand, readers sceptical of the ideas sketched in this subsection may take Section 3 as it is, while others have the beginnings of an analysis of how and why intervals come into play at all.

\subsection{Outlook}

Let's take a step back and think about what an analysis of quantifiers in than-clauses in terms of selection achieves - beyond the empirical coverage of the mostly well-known set of data that I have been concerned with above.

Compared to its theoretical competitors, it primarily removes quantifiers in than-clauses from the realm of scope interaction phenomena. For example, the interpretive behaviour of quantifiers in than-clauses cannot be seen as an instance of the Heim/Kennedy generalization (Kennedy 1997; Heim 2001). The analysis I've given in Section 3 violates this generalization.

(188) Heim/Kennedy generalization: [ DegP ... [ QP [... $\left.\left.\left.\mathrm{t}_{\text {DegP }} \ldots\right] \ldots\right]\right]$

(189) a. than [1 [every girl is $t_{1}$ tall]]

b. $\lambda D$. for every girl $x$ : Height $(x) \in D$

The Heim/Kennedy generalization is motivated in particular by quantifiers in the matrix clause of comparatives. Suppose that the behaviour of quantifiers in the matrix clause relative to degree operators is regulated by a scope constraint deriving the Heim/Kennedy generalization. Then there would be no theoretical connection between this and than-clause quantifiers. We would accordingly expect empirical differences between quantifiers in main clause vs. than-clause. On the other hand, if one were to extend the requirement of finding a definite degree from the than-clause to the main clause (a good way of ensuring applicability of the lexical entry in (172c), note), a parallel analysis could still be pursued. (See once more Heim 2009 for a sketch of such an analysis.) There are some striking similarities between main clause and than-clause quantifiers that motivate such a step, in 
particular (190), (191) below: Both sentences in (190) have an interpretation that talks about the minimum requirement length of the paper, and neither sentence in (191) does.

(190) a. The paper is longer than it is required to be.

b. The paper is required to be less long than that.

(191) a. The paper is longer than it is supposed to be.

b. The paper is supposed to be less long than that.

But there are also apparent mismatches:

(192) a. Hier ist es schöner als anderswo. here is it nicer than elsewhere 'It is nicer here than it is elsewhere.'

b. ok: It is nicer here than it is in the most beautiful other place.

(193) a. Anderswo ist es weniger schön als hier. elsewhere is it less nice than here 'It is less nice elsewhere than it is here.'

b. ??The most beautiful other place is less nice than it is here.

(194) a. Sam war schneller als jemand anderes. Sam was faster than someone other 'Sam was faster than another person.'

b. ok: Sam was faster than the fastest other person.

(195) a. Jemand anderes war weniger schnell als Sam. Someone other was less fast than Sam 'Another person was less fast than Sam.'

b. ??The fastest other person was less fast than Sam.

At this point, I do acknowledge interesting empirical parallels, but I am also worried about apparent differences. I would not wish to be committed at present to claiming that quantifiers in the main clause behave in the same way as quantifiers in the than-clause, or that they don't, and will remain neutral as to whether the analysis developed here should be extended to cover matrix clause quantifiers as well.

Instead of making a connection to scope interaction phenomena, the present analysis is based on a plural/mass-semantics related vagueness plus semantic and pragmatic glue. It makes the interpretation of quantifiers in than-clauses more of a coercion-like phenomenon. Perhaps the variable and partly messy nature of the data can motivate the nature of the analysis. 
Quantifiers in than-clauses

\section{References}

Beck, Sigrid. 2001. Reciprocals are definites. Natural Language Semantics 9(1). 69-138. doi:10.1023/A:1012203407127.

Beck, Sigrid. 2009. Comparatives and superlatives. To appear in Klaus von Heusinger, Claudia Maidenborn, and Paul Portner (eds.), Handbook of semantics: An international handbook of natural language meaning. Berlin: Mouton de Gruyter.

Beck, Sigrid \& Hotze Rullmann. 1999. A flexible approach to exhaustivity in questions. Natural Language Semantics 7(3). 249-298. doi:10.1023/A:1008373224343.

Beck, Sigrid \& Uli Sauerland. 200o. Cumulation is needed: A reply to Winter 2000. Natural Language Semantics 8(4). 349-371. doi:10.1023/A:1011240827230.

Bošković, Željko \& Jon Gajewski. 20o8. Semantic correlates of the NP/DP parameter. Proceedings of the North East Linguistics Society 39. URL http://gajewski.uconn.edu/papers/NELS39paper.pdf.

Cresswell, Max J. 1977. The semantics of degree. In Barbara H. Partee (ed.), Montague grammar, 261-292. Academic Press.

Dalrymple, Mary, Makoto Kanazawa, Yookyung Kim, Sam Mchombo \& Stanley Peters. 1998. Reciprocal expression and the concept of reciprocity. Linguistics and Philosophy 21(2). 159-210. doi:10.1023/A:1005330227480.

Endriss, Cornelia. 2009. Quantificational topics: A scopal treatment of exceptional wide scope phenomena (Studies in Linguistics and Philosophy (SLAP) 86). Springer. doi:10.1007/978-90-481-2303-2.

von Fintel, Kai \& Sabine Iatridou. 2005. What to do if you want to go to Harlem: Anankastic conditionals and related matters. URL http://mit. edu/fintel/fintel-iatridou-2005-harlem.pdf. Ms, MIT.

Fox, Danny. 2007. Free choice and the theory of scalar implicatures. In Uli Sauerland \& Penka Stateva (eds.), Presupposition and implicature in compositional semantics, 537-586. New York: Palgrave Macmillan.

Fox, Danny \& Martin Hackl. 2006. The universal density of measurement. Linguistics and Philosophy 29(5). 537-586. doi:10.1007/s10988-006-9004-4. Gajewski, Jon. 2008. More on quantifiers in comparative clauses. Proceedings of Semantics and Linguistic Theory 18. doi:1813/13043.

Hackl, Martin. 2001a. Comparative quantifiers. Ph.D. thesis, Massachusetts Institute of Technology. URL http://hdl.handle.net/1721.1/8765.

Hackl, Martin. 2001b. A comparative syntax for comparative quantifiers. 
Sigrid Beck

Proceedings of the North East Linguistics Society 31.

Hackl, Martin. 2009. On the grammar and processing of proportional quantifiers: most versus more than half. Natural Language Semantics 17(1). 63-98. doi:10.1007/s11050-008-9039-x.

Heim, Irene. 1982. The semantics of definite and indefinite noun phrases. Ph.D. thesis, University of Massachusetts at Amherst. URL http:// semanticsarchive.net/Archive/TkoZmYyY.

Heim, Irene. 1994. Interrogative semantics and Karttunen's semantics for know. In Rhonna Buchalla \& Anita Mittwoch (eds.), The proceedings of the conference of the Israel Association for Theoretical Linguistics (IATL 1), 128-144. Hebrew University of Jerusalem. URL http://semanticsarchive. net/Archive/jUzYjkiO.

Heim, Irene. 2001. Degree operators and scope. In Caroline Féry \& Wolfgang Sternefeld (eds.), Audiatur vox sapientiae: A festschrift for Arnim von Stechow, 214-239. Berlin: Akademie Verlag.

Heim, Irene. 2006a. Little. Proceedings of Semantics and Linguistic Theory 16. doi:1813/7579.

Heim, Irene. 2006b. Remarks on comparative clauses as generalized quantifiers. URL http://semanticsarchive.net/Archive/mJiMDBIN. Ms, MIT.

Heim, Irene. 2009. A unified account? Handout for 'Topics in Semantics', MIT.

Heim, Irene \& Angelika Kratzer. 1998. Semantics in generative grammar. Oxford: Blackwell.

Hellan, Lars. 1981. Towards an integrated analysis of comparatives (Ergebnisse und Methoden moderner Sprachwissenschaft 11). Tübingen: Narr.

Hoeksema, Jack. 1983. Negative polarity and the comparative. Natural Language and Linguistic Theory 1(3). 403-434. doi:10.1007/BFoo142472.

Jacobson, Pauline. 1995. On the quantificational force of English free relatives. In Emmon Bach, Eloise Jelinek, Angelika Kratzer \& Barbara H. Partee (eds.), Quantification in natural languages (Studies in Linguistics and Philosophy (SLAP) 54), 451-486. Dordrecht: Kluwer.

Kennedy, Chris. 1997. Projecting the adjective: The syntax and semantics of gradability and comparison. Ph.D. thesis, University of California, Santa Cruz.

Klein, Ewan. 1991. Comparatives. In von Stechow \& Wunderlich (1991), chap. 32, 673-691.

Krasikova, Sveta. 2008. Quantifiers in comparatives. Proceedings of Sinn und Bedeutung 12. 337-352. URL http://www.hf.uio.no/ilos/forskning/ 
Quantifiers in than-clauses

konferanser/SuB12/proceedings/krasikova_337-352.pdf.

Krasikova, Sveta \& Ventsislav Zhechev. 2006. You only need a scalar only. Proceedings of Sinn und Bedeutung 10. URL http://www.sfb441.uni-tuebingen. de/bio/Pubs/KrasikovaZhechev_SuBo5.pdf.

Kratzer, Angelika. 1991. Modality. In von Stechow \& Wunderlich (1991), 639-650.

Kratzer, Angelika. 1998. Scope or pseudoscope? are there wide-scope indefinites? In Susan Rothstein (ed.), Events and grammar. Dordrecht: Kluwer.

Krifka, Manfred. 1999. At least some determiners aren’t determiners. In Ken Turner (ed.), The semantics/pragmatics interface from different points of view (Current Research in the Semantics/Pragmatics Interface 1), 257-291. Elsevier.

Krifka, Manfred. 2007. Approximate interpretation of number words: A case for strategic communication. In Gerlof Bouma, Irene Maria Krämer \& Joost Zwarts (eds.), Cognitive foundations of interpretation (Verhandelingen der Koninklijke Nederlandse Akademie van Wetenschappen, Afd. Letterkunde 190), 111-126. Amsterdam: Royal Netherlands Academy of Arts and Sciences.

Larson, Richard K. 1988. Scope and comparatives. Linguistics and Philosophy 11(1). 1-26. doi:10.1007/BFoo635755.

Link, Godehard. 1983. The logical analysis of plurals and mass terms: A lattice-theoretical approach. In Rainer Bäuerle, Christoph Schwarze \& Arnim von Stechow (eds.), Meaning, use, and interpretation of language, Grundlagen der Kommunikation und Kognition, 302-323. de Gruyter.

May, Robert. 1985. Logical form: Its structure and derivation (Linguistic Inquiry Monographs 12). Cambridge, MA: MIT Press.

Meier, Cécile. 2002. Maximality and minimality in comparatives. Sinn und Bedeutung 6. 275-287. URL http://www.phil-fak.uni-duesseldorf.de/asw/ gfs/common/procSuB6/pdf/articles/MeierSuB6.pdf.

Partee, Barbara H. 1984. Compositionality. In Fred Landman \& Frank Veltman (eds.), Varieties of formal semantics (Groningen-Amsterdam Studies in Semantics (GRASS) 3), 281-311. Dordrecht: Foris.

Reinhart, Tanya. 1992. Wh-in-situ: An apparent paradox. Proceedings of the Amsterdam Colloquium 8. 483-492.

van Rooij, Robert. 2008. Comparatives and quantifiers. Empirical Issues in Syntax and Semantics 7. 423-444. URL http://www.cssp.cnrs.fr/eiss7/ van-rooij-eiss7.pdf. 
Rullmann, Hotze. 1995. Maximality in the semantics of wh-constructions. Ph.D. thesis, University of Massachusetts at Amherst. URL http://scholarworks. umass.edu/dissertations/AAI9524743/.

Sauerland, Uli. 2008. Intervals have holes: A note on comparatives with differentials. Ms, ZAS Berlin.

Schwarzschild, Roger. 1996. Pluralities (Studies in Linguistics and Philosophy (SLAP) 61). Kluwer.

Schwarzschild, Roger. 2004. Scope splitting in the comparative. URL http: //www.rci.rutgers.edu/ tapuz/MITo4.pdf. Handout from a colloquium talk at MIT.

Schwarzschild, Roger. 2008. The semantics of comparatives and other degree constructions. Language and Linguistics Compass 2(2). 308-331. doi:10.1111/j.1749-818X.2007.00049.x.

Schwarzschild, Roger \& Karina Wilkinson. 2002. Quantifiers in comparatives: A semantics of degree based on intervals. Natural Language Semantics 10(1). 1-41. doi:10.1023/A:1015545424775.

Seuren, Pieter A.M. 1978. The structure and selection of positive and negative gradable adjectives. In Donka Farkas, Wesley M. Jacobsen \& Karol W. Todrys (eds.), Papers from the Parasession on the Lexicon, Chicago Linguistic Society, April 14-15, 1978 (CLS 14), 336-346.

von Stechow, Arnim. 1984. Comparing semantic theories of comparison. Journal of Semantics 3(1-2). 1-77. doi:10.1093/jos/3.1-2.1.

von Stechow, Arnim. 1995. Lexical decomposition in syntax. In Urs Egli, Peter E. Pause, Christoph Schwarze, Arnim von Stechow \& Götz Wienold (eds.), Lexical knowledge in the organization of language (Current Issues in Linguistic Theory 114), 81-118. John Benjamins.

von Stechow, Arnim \& Dieter Wunderlich (eds.). 1991. Semantics: An international handbook of contemporary research. Berlin: de Gruyter.

Prof. Dr. Sigrid Beck

Chair of Descriptive and Theoretical Linguistics

Englisches Seminar

Universität Tübingen

Wilhelmstr. 50

72074 Tübingen

Germany

sigrid.beck@uni-tuebingen.de 